\title{
Analogous Synaptic Plasticity Profiles Emerge from Disparate Channel Combinations
}

\author{
Arun Anirudhan ${ }^{1,2,3}$ and ${ }^{\circledR}$ Rishikesh Narayanan ${ }^{1}$ \\ ${ }^{1}$ Cellular Neurophysiology Laboratory, Molecular Biophysics Unit, Indian Institute of Science, Bangalore 560 012, India, ${ }^{2}$ School of Biotechnology, National \\ Institute of Technology, Calicut 637 601, India, and ${ }^{3}$ Bio-Medical Technology Wing, Sree Chitra Thirunal Institute for Medical Science \& Technology, \\ Trivandrum 695 012, India
}

\begin{abstract}
An open question within the Bienenstock-Cooper-Munro theory for synaptic modification concerns the specific mechanism that is responsible for regulating the sliding modification threshold (SMT). In this conductance-based modeling study on hippocampal pyramidal neurons, we quantitatively assessed the impact of seven ion channels ( $R$ - and $T$-type calcium, fast sodium, delayed rectifier, $A$-type, and small-conductance calcium-activated (SK) potassium and HCN) and two receptors (AMPAR and NMDAR) on a calcium-dependent Bienenstock-Cooper-Munro-like plasticity rule. Our analysis with $R$ - and $T$-type calcium channels revealed that differences in their activation-inactivation profiles resulted in differential impacts on how they altered the SMT. Further, we found that the impact of SK channels on the SMT critically depended on the voltage dependence and kinetics of the calcium sources with which they interacted. Next, we considered interactions among all the seven channels and the two receptors through global sensitivity analysis on 11 model parameters. We constructed 20,000 models through uniform randomization of these parameters and found 360 valid models based on experimental constraints on their plasticity profiles. Analyzing these 360 models, we found that similar plasticity profiles could emerge with several nonunique parametric combinations and that parameters exhibited weak pairwise correlations. Finally, we used seven sets of virtual knock-outs on these 360 models and found that the impact of different channels on the SMT was variable and differential. These results suggest that there are several nonunique routes to regulate the SMT, and call for a systematic analysis of the variability and state dependence of the mechanisms underlying metaplasticity during behavior and pathology.
\end{abstract}

Key words: BCM plasticity rule; hippocampus; homeostasis; ion channels; metaplasticity; synaptic plasticity

\section{Introduction}

Plasticity in voltage- and calcium-gated ion channels induces synaptic metaplasticity through changes in intrinsic neuronal excitability (Abraham and Bear, 1996; Abraham and Tate, 1997; Watanabe et al., 2002; Johnston et al., 2003; Nolan et al., 2004; Magee and Johnston, 2005; Chen et al., 2006; Abraham, 2008; Narayanan and Johnston, 2010; Adelman et al., 2012; Cooper and Bear, 2012; Honnuraiah and Narayanan, 2013; Hulme et al., 2013; Sehgal et al., 2013). Although the impact of certain voltagegated ion channels on synaptic plasticity profiles has been quantitatively assessed (Narayanan and Johnston, 2010; Ashhad and Narayanan, 2013; Honnuraiah and Narayanan, 2013), the role of interactions between several coexpressing dendritic ion channels

Received 0ct. 13, 2014; revised Jan. 19, 2015; accepted Feb. 11, 2015.

Author contributions: R.N. designed research; A.A. and R.N. performed research;A.A. and R.N. analyzed data; R.N. wrote the paper.

This work was supported by the International Human Frontier Science Program Organization to R.N., the Department of Science and Technology to R.N., the Indian Institute of Science to R.N., and a visiting fellowship from the Indian National Science Academy to A.A. We thank members of the cellular neurophysiology laboratory for their constant support and help through the course of this project and for helpful comments on a draft version of the manuscript.

The authors declare no competing financial interests.

Correspondence should be addressed to Dr. Rishikesh Narayanan, Molecular Biophysics Unit, Indian Institute of Science, Bangalore 560 012, India. E-mail: rishi@mbu.iisc.ernet.in.

DOI:10.1523/JNEUROSCI.4223-14.2015

Copyright $\odot 2015$ the authors $\quad 0270-6474 / 15 / 354691-15 \$ 15.00 / 0$ in inducing metaplasticity or how such interactions contribute or hamper the maintenance of plasticity profile homeostasis have not been analyzed. Further, plasticity during learning and pathology also span intrinsic components apart from changes in synaptic structures (Turrigiano et al., 1994; Johnston et al., 2003; Frick and Johnston, 2005; Magee and Johnston, 2005; Bernard et al., 2007; Kim and Linden, 2007; Johnston and Narayanan, 2008; Sjöström et al., 2008; Mozzachiodi and Byrne, 2010; Remy et al., 2010; Shah et al., 2010; Turrigiano, 2011; Lee and Jan, 2012; Narayanan and Johnston, 2012; Brager and Johnston, 2014; Shah, 2014). Although the synergy between synaptic and intrinsic plasticity has been quantitatively assessed in terms of its impact on activity homeostasis and variability (LeMasson et al., 1993; Siegel et al., 1994; Liu et al., 1998; Marder and Prinz, 2002; Marder and Goaillard, 2006; Triesch, 2007; Marder and Taylor, 2011; Marder, 2011; Honnuraiah and Narayanan, 2013; O'Leary et al., 2014), the roles of such synergy in regulating metaplasticity and plasticity profile homeostasis have not been assessed.

To fill these lacunae, in this study, we use conductance-based models to quantitatively assess the effect of pairwise and global interactions among dendritically expressed ion channels on plasticity profiles within a calcium-dependent Bienenstock-CooperMunro (BCM)-like framework (Bienenstock et al., 1982; Lisman, 1989, 2001; Shouval et al., 2002; Narayanan and Johnston, 2010; Cooper and Bear, 2012). We first analyzed the sensitivity of the 

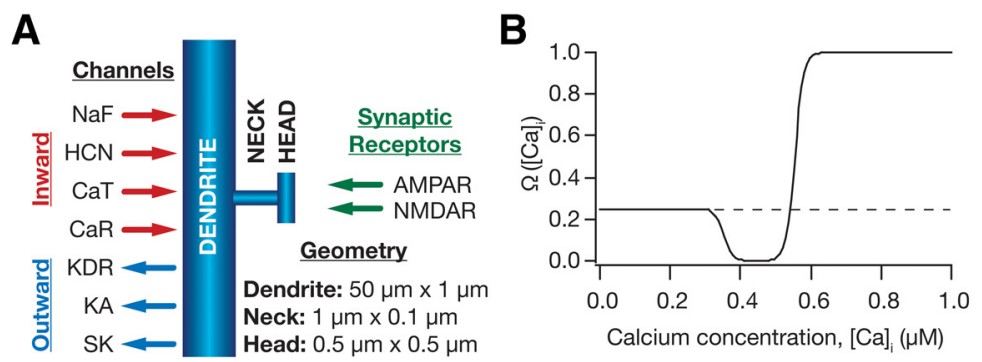

D

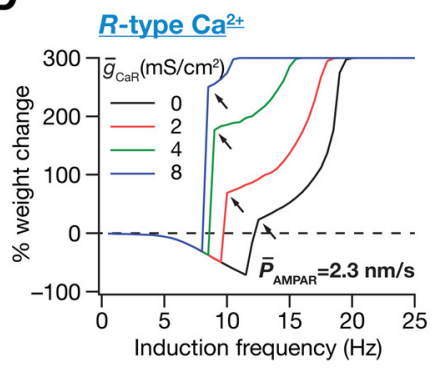

E

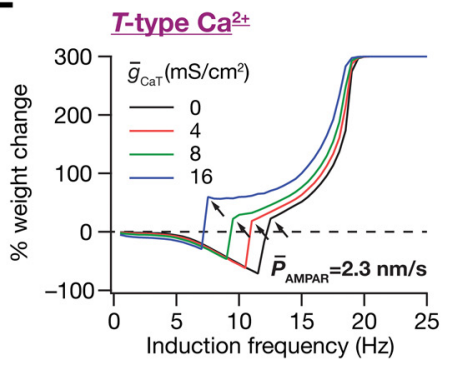

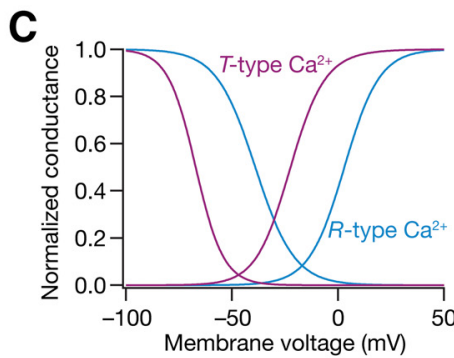

$\mathbf{F}$

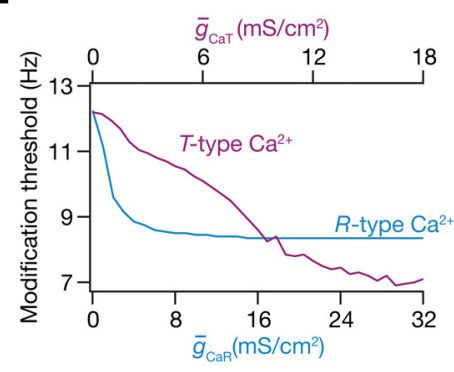

Figure 1. R-type and $T$-type calcium channels differentially modulated the synaptic plasticity profile. $A$, Depiction of the three-compartment model showing a dendritic segment attached to a spine that contains a neck and a head. The inward and outward currents present in these compartments are shown along with the synapse on the spine head containing AMPA and NMDA receptors. $\boldsymbol{B}$, The form of the $\Omega$ function that controls the strength and direction of synaptic plasticity as a function of cytosolic calcium concentration (Eq. 14). $\boldsymbol{C}$, Differences in the voltage-dependent activation and inactivation profiles of the hippocampal $R$-type (CaR) and $T$-type (CaT) calcium channels. $\boldsymbol{D}, \boldsymbol{E}$, Synaptic plasticity profile as a function of various induction frequencies (900 pulses protocol) plotted for different values of $\operatorname{CaR}(\boldsymbol{D})$ and $\mathrm{CaT}(\boldsymbol{E})$ conductance density. Black arrows indicate sharp transitions in the synaptic plasticity profiles and correspond to induction frequency values where spikes were generated in response to synaptic stimulation. $\boldsymbol{F}$, Modification threshold plotted as functions of CaR and CaT conductance density. The analyses presented in this figure correspond to models that contained the spike-generating conductances ( $\mathrm{NaF}$ and $\mathrm{KDR}$ ) and one of $\mathrm{CaR}$ or $\mathrm{CaT}$ channels.

BCM-like plasticity profile on several combinations of the $T$ (CaT) and R-type (CaR) calcium, and the small conductance calcium-activated potassium (SK) channels, all of which have been implicated in regulating synaptic plasticity (Golding et al., 2002; Yasuda et al., 2003; Lin et al., 2008; Takahashi and Magee, 2009; Adelman et al., 2012). Next, we turned to the powerful global sensitivity analysis (Marder and Goaillard, 2006; Marder and Taylor, 2011; Marder, 2011) on seven different ion channels to expand interactions among ion channels beyond pairwise interactions (Narayanan and Johnston, 2010; Ashhad and Narayanan, 2013; Honnuraiah and Narayanan, 2013), and assessed the role of cross-channel interactions in altering synaptic plasticity profiles. Finally, we used the virtual knock-out model (VKM) analyses technique introduced in (Rathour and Narayanan, 2014) to assess the relative impact of each ion channel on the synaptic plasticity profile.

Our results suggest that the voltage dependence and kinetics of ion channels play critical roles in how they interact with other ion channels and in the quantitative manner in which they alter the synaptic plasticity profile together with such interactions. These results also revealed that individual or pairwise channelostasis are nonessential in the robust emergence of identical synaptic plasticity profiles, and a collective form of channelostasis might be a distinct alternative in achieving plasticity profile homeostasis. Together, we postulate that identical metaplastic shifts could be achieved by recruiting disparate channels/receptors and that the specific mechanism recruited by a neuron toward regulating the sliding modification threshold is variable and state-dependent.

\section{Models and Methods}

A three compartmental (Fig. 1A) conductance-based neuronal model was used for all simulations. The reason behind the choice of a simplified model for our simulations was to reduce computational complexity and to assess kinetic interactions among channels precluding the influence of morphological factors. Specifically, given the computational complexity associated with the plasticity paradigms and the global sensitivity analysis (detailed below), performing these with a morphological realistic model would constitute an enormous increase in computational cost as a consequence of the increase in the number of neuronal compartments. Second, as our focus is on understanding the role of different voltage-gated ion channels in effectuating metaplasticity, we reasoned that the question under consideration would be best addressed if the focus remained on channel kinetics (Rathour and Narayanan, 2012) without the additional complexity of the well-established influence of morphological parameters on excitability and plasticity (Mainen and Sejnowski, 1996; Vetter et al., 2001; Krichmar et al., 2002; van Ooyen et al., 2002; Schaefer et al., 2003; Sjöström et al., 2008; Narayanan and Chattarji, 2010; van Elburg and van Ooyen, 2010; Ferrante et al., 2013).

The passive parameters associated with the model were as follows: $R_{m}=14 \mathrm{k} \Omega \mathrm{cm}^{2}$ and $C_{\mathrm{m}}=1.5 \mu \mathrm{F} / \mathrm{cm}^{2}$. Fast $\mathrm{Na}^{+}(\mathrm{NaF})$, delayed rectifier $\mathrm{K}^{+}(\mathrm{KDR})$, small-conductance calcium-activated $\mathrm{K}^{+}(\mathrm{SK})$, $A$-type $\mathrm{K}^{+}(\mathrm{KA}), \quad R$-type $(\mathrm{CaR}) \mathrm{Ca}^{2+}, T$-type $\mathrm{Ca}^{2+}(\mathrm{CaT})$, and hyperpolarization-activated cyclic-nucleotide gated (HCN) channels were introduced as Hodgkin-Huxley-type models, with kinetics adopted from experimental measurements of these channels in hippocampal neurons (Yuen and Durand, 1991; Magee and Johnston, 1995; Hoffman et al., 1997; Magee, 1998; Migliore et al., 1999; Gasparini et al., 2004; Narayanan and Johnston, 2010). The rationale behind the choice of these channels arises from their dendritic expression profiles (Magee and Johnston, 1995; Sah and Isaacson, 1995; Hoffman et al., 1997; Magee, 1998; Poolos and Johnston, 1999; Sah and Clements, 1999; Chen and Johnston, 2004; Ngo-Anh et al., 2005; Lai and Jan, 2006; Nusser, 2012) and their experimentally identified roles in altering synaptic plasticity profiles in CA1 pyramidal neurons (Golding et al., 2002; Yasuda et al., 2003; Nolan et al., 2004; Ngo-Anh et al., 2005; Chen et al., 2006; Lin et al., 2008; Takahashi and Magee, 2009; Adelman et al., 2012). Default values of maximum conductance densities are given in Table 1. The 6-state kinetic model for SK channels was adopted from experimental measurements in hippocampal neurons (Sah and Isaacson, 1995; Sah and Clements, 1999). Reversal potentials for the $\mathrm{HCN}, \mathrm{K}^{+}$, and $\mathrm{Na}^{+}$channels, respectively, were $E_{\mathrm{h}}=-30 \mathrm{mV}, E_{\mathrm{K}}=-90 \mathrm{mV}, E_{\mathrm{Na}}=55 \mathrm{mV}$. Given the steep 
Table 1. Parameter values in the baseline model and the range used in generating the uniformly random population of models

\begin{tabular}{lccc}
\hline Parameter, symbol (unit) & Baseline & Lower bound & Upper bound \\
\hline AMPAR permeability, $\bar{P}_{A M P A R}(\mathrm{~nm} / \mathrm{s})$ & 2.4 & 0.2 & 4 \\
NMDAR:AMPAR ratio, NAR & 1.5 & 1 & 2.5 \\
NMDAR decay time constant, $\tau_{N M D A R}(\mathrm{~ms})$ & 50 & 50 & 150 \\
Calcium decay time constant, $\tau_{C a}(\mathrm{~ms})$ & 30 & 30 & 150 \\
NaF conductance density, $\bar{g}_{N a F}\left(\mathrm{mS} / \mathrm{cm}^{2}\right)$ & 40 & 10 & 70 \\
KDR conductance density, $\bar{g}_{K D R}\left(\mathrm{mS}^{2} \mathrm{~cm}^{2}\right)$ & 5 & 2 & 8 \\
CaR conductance density, $\bar{g}_{C a R}\left(\mathrm{mS} / \mathrm{cm}^{2}\right)$ & 9 & 1 & 20 \\
CaT conductance density, $\bar{g}_{C a T}\left(\mathrm{mS} / \mathrm{cm}^{2}\right)$ & 7 & 1 & 20 \\
SK conductance density, $\bar{g}_{S K}\left(\mu \mathrm{S} / \mathrm{cm}^{2}\right)$ & 9 & 1 & 20 \\
KA conductance density, $\bar{g}_{K A}\left(\mathrm{mS} / \mathrm{cm}^{2}\right)$ & 2 & 0.2 & 20 \\
HCN conductance density, $\bar{g}_{h}\left(\mu S / \mathrm{cm}^{2}\right)$ & 3.5 & 0.3 & 30 \\
\hline
\end{tabular}

transmembrane concentration gradient associated with the calcium ion $\left([\mathrm{Ca}]_{\mathrm{i}}=100 \mathrm{nM},[\mathrm{Ca}]_{\mathrm{o}}=2 \mathrm{~mm}\right)$, all calcium channels were modeled within the Goldman-Hodgkin-Katz convention (Goldman, 1943; Hodgkin and Katz, 1949). All simulations were performed at $-65 \mathrm{mV}$ in the NEURON simulation environment (Carnevale and Hines, 2006), with an integration time constant of $25 \mu \mathrm{s}$. All analyses were performed in custom-written software in Igor Pro (Wavemetrics).

Synapse model. A synapse was modeled as a colocalized combination of NMDA and AMPA receptor currents (Fig. 1A), with the default value of NMDAR:AMPAR ratio set at 1.5. The kinetics of AMPA and NMDA receptor currents were adopted from previous literature (Narayanan and Johnston, 2010; Ashhad and Narayanan, 2013; Honnuraiah and Narayanan, 2013) and are detailed below. The current through the NMDA receptor, as a function of voltage and time, was dependent on three ions: sodium, potassium, and calcium. Consequently, as per the GoldmanHodgkin-Katz convention (Goldman, 1943; Hodgkin and Katz, 1949; Mayer and Westbrook, 1987; Canavier, 1999; Narayanan and Johnston, 2010; Ashhad and Narayanan, 2013; Honnuraiah and Narayanan, 2013):

$$
I_{N M D A}(v, t)=I_{N M D A}^{N a}(v, t)+I_{N M D A}^{K}(v, t)+I_{N M D A}^{C a}(v, t)
$$

where

$$
\begin{aligned}
& I_{N M D A}^{N a}(v, t) \\
& =\bar{P}_{N M D A R} P_{N a} s(t) M g B(v) \frac{v F^{2}}{R T}\left(\frac{[N a]_{i}-[N a]_{o} \exp \left(-\frac{v F}{R T}\right)}{1-\exp \left(-\frac{v F}{R T}\right)}\right)
\end{aligned}
$$

$I_{N M D A}^{K}(v, t)$

$$
=\bar{P}_{N M D A R} P_{K} s(t) M g B(v) \frac{v F^{2}}{R T}\left(\frac{[K]_{i}-[K]_{o} \exp \left(-\frac{v F}{R T}\right)}{1-\exp \left(-\frac{v F}{R T}\right)}\right)
$$

$I_{N M D A}^{C a}(v, t)$

$$
=\bar{P}_{N M D A R} P_{C a} s(t) M g B(v) \frac{4 v F^{2}}{R T}\left(\frac{[C a]_{i}-[C a]_{o} \exp \left(-\frac{2 v F}{R T}\right)}{1-\exp \left(-\frac{2 v F}{R T}\right)}\right)
$$

where $\bar{P}_{\text {NMDAR }}$ is the maximum permeability of the NMDA receptor. The relative permeability ratios are $P_{\mathrm{Ca}}=10.6, P_{\mathrm{Na}}=1$, and $P_{K}=1$ because of the permeability of the NMDA receptor to different ions being $P_{C a}$ : $P_{N a}: P_{K}=10.6: 1: 1$. Default values of concentrations were (in $\mathrm{mm}$ ) as follows: $[\mathrm{Na}]_{\mathrm{i}}=18,[\mathrm{Na}]_{0}=140,[\mathrm{~K}]_{\mathrm{i}}=140,[\mathrm{~K}]_{\mathrm{o}}=5,[\mathrm{Ca}]_{\mathrm{i}}=100 \times$ $10^{-6},[\mathrm{Ca}]_{\mathrm{o}}=2$. The concentration for sodium was set such that equilibrium potential was at $55 \mathrm{mV}$ and that for potassium was at $-90 \mathrm{mV}$.
$M g B(v)$ governs the magnesium dependence of the NMDAR current, given as (Jahr and Stevens, 1990) the following:

$$
\operatorname{MgB}(v)=\left(1+\frac{[M g]_{o} \exp (-0.062 v)}{3.57}\right)
$$

with the default value of $[\mathrm{Mg}]_{o}$ set at $2 \mathrm{~mm} . s(t)$ governs the kinetics of the NMDAR current, and is given as follows:

$$
s(t)=a\left(\exp \left(-\frac{t}{\tau_{d}}\right)-\exp \left(-\frac{t}{\tau_{r}}\right)\right)
$$

where $a$ is a normalization constant, making sure that $0 \leq s(t) \leq 1, \tau_{d}$ is the decay time constant, $\tau_{r}$ is rise time, with $\tau_{r}=5 \mathrm{~ms}$, and default $\tau_{d}=$ 50 ms (Dingledine et al., 1999; Narayanan and Johnston, 2010; Ashhad and Narayanan, 2013; Honnuraiah and Narayanan, 2013).

Current through the AMPA receptor was modeled as the sum of currents carried by these sodium and potassium ions:

$$
I_{A M P A}(v, t)=I_{A M P A}^{N a}(v, t)+I_{A M P A}^{K}(v, t)
$$

where

$$
\begin{gathered}
I_{A M P A}^{N a}(v, t)=\bar{P}_{A M P A R} w P_{N a} s(t) \frac{v F^{2}}{R T}\left(\frac{[N a]_{i}-[N a]_{o} \exp \left(-\frac{v F}{R T}\right)}{1-\exp \left(-\frac{v F}{R T}\right)}\right) \\
I_{A M P A}^{K}(v, t)=\bar{P}_{A M P A R} w P_{K} s(t) \frac{v F^{2}}{R T}\left(\frac{[K]_{i}-[K]_{o} \exp \left(-\frac{v F}{R T}\right)}{1-\exp \left(-\frac{v F}{R T}\right)}\right)
\end{gathered}
$$

where $\bar{P}_{A M P A R}$ is the maximum permeability of the AMPA receptor, whose default value was set at $24 \mathrm{~nm} / \mathrm{s}$. The relative permeability ratios $P_{\mathrm{Na}}$ and $P_{K}$ were equal and set to 1 (Dingledine et al., 1999). $w$ is the weight parameter that undergoes activity-dependent plasticity (see below). $s(t)$ was the same as that for the NMDA receptor, but with $\tau_{\mathrm{r}}=2 \mathrm{~ms}$ and $\tau_{\mathrm{d}}=10 \mathrm{~ms}$ (Dingledine et al., 1999; Narayanan and Johnston, 2010).

The evolution of intracellular calcium as a function of calcium current (through NMDARs and voltage-gated calcium channels) and its buffering was modeled as described previously (Poirazi et al., 2003; Narayanan and Johnston, 2010; Honnuraiah and Narayanan, 2013):

$$
\frac{d[\mathrm{Ca}]_{i}}{d t}=-\frac{10000 I_{N M D A}^{C a}}{3.6 d p t F}+\frac{[\mathrm{Ca}]_{\infty}-[\mathrm{Ca}]_{i}}{\tau_{C a}}
$$

where $F$ is Faraday's constant, the default value of the calcium decay time constant $\tau_{C a}=30 \mathrm{~ms}, d p t=0.1 \mu \mathrm{m}$ is the depth of the shell, and $[\mathrm{Ca}]_{\infty}=100 \mathrm{~nm}$ is the steady-state value of $[\mathrm{Ca}]_{\mathrm{i}}$.

Construction of synaptic plasticity profile. The synaptic weight parameter $w$ (see Eqs. 8 and 9) was updated as a function of intracellular calcium, following the calcium control hypothesis (Lisman, 1989, 2001; Shouval et al., 2002). Specifically,

$$
\frac{d w}{d t}=\eta\left([C a]_{i}\right)\left(\Omega\left([C a]_{i}-w\right)\right)
$$

where, $\eta\left([\mathrm{Ca}]_{\mathrm{i}}\right)$ is the calcium-dependent learning rate, inversely related to the learning time constant $\tau\left([\mathrm{Ca}]_{\mathrm{i}}\right)$ :

$$
\begin{gathered}
\eta\left([\mathrm{Ca}]_{i}\right)=\frac{1}{\tau\left([\mathrm{Ca}]_{i}\right)} \\
\tau\left([\mathrm{Ca}]_{i}\right)=P_{1}+\frac{P_{2}}{P_{3}[\mathrm{Ca}]_{i}^{P_{4}}}
\end{gathered}
$$


with $P_{1}=1 \mathrm{~s}, P_{2}=0.1 \mathrm{~s}, P_{3}=P_{2} \times 10^{-4}, P_{4}=3 . \eta([\mathrm{Ca}] \mathrm{i})$ had the following form:

$$
\begin{aligned}
& \Omega\left([C a]_{i}\right)=0.25+\frac{1}{1+\exp \left(-\beta_{2}\left([\mathrm{Ca}]_{i}-\alpha_{2}\right)\right)} \\
&-0.25 \frac{1}{1+\exp \left(-\beta_{1}\left([\mathrm{Ca}]_{i}-\alpha_{1}\right)\right)}
\end{aligned}
$$

with $\alpha_{1}=0.35, \alpha_{2}=0.55, \beta_{1}=80, \beta_{2}=80$ (Fig. $1 B$ ). In all of the above weight update equations, for compatibility, $[\mathrm{Ca}]_{\mathrm{i}}$ is set as $[\mathrm{Ca}]_{\mathrm{i}}-100 \mathrm{nM}$. The default initial value of $w, w_{\text {init }}$, was set at 0.25 .

Using this framework, we analyzed the direction and strength of plasticity in $w$ by presenting stimuli made up of 900 pulses at various induction frequencies $\left(f_{\mathrm{i}}\right.$ spanning $0.5-25 \mathrm{~Hz}$ ), an experimentally and computationally well-established plasticity protocol (Dudek and Bear, 1992; Shouval et al., 2002; Johnston et al., 2003; Narayanan and Johnston, 2010; Cooper and Bear, 2012; Ashhad and Narayanan, 2013; Honnuraiah and Narayanan, 2013). The evolution of synaptic weight (Eq. 11) was monitored, and the final weight at the end of the induction protocol was plotted as a function of the induction frequency. The percentage difference between this final weight and the initial weight (0.25) was plotted against the induction frequency of the stimulus pulses to obtain the synaptic plasticity profile as a function of induction frequency (Shouval et al., 2002; Narayanan and Johnston, 2010; Honnuraiah and Narayanan, 2013). The induction frequency at which this plasticity profile transitioned from depression to potentiation was defined as the modification threshold (Dudek and Bear, 1992; Shouval et al., 2002; Johnston et al., 2003; Narayanan and Johnston, 2010; Cooper and Bear, 2012; Ashhad and Narayanan, 2013; Honnuraiah and Narayanan, 2013). The computational complexity of this process is enormous given that the construction of each profile required stimulating the synapses with 900 pulses for each of the 50 induction frequencies $\left(f_{\mathrm{i}}\right.$ spanning $0.5-25 \mathrm{~Hz} ; 0.5 \mathrm{~Hz}$ increment). The simulation periods were especially longer when the model contained all seven ion channels and the two receptors, especially for lower induction frequencies where 900 pulses implied a long simulation time.

Generation of random models and their validation. To assess the crosssensitivities and interactions among the different ion channels and analyze their specific roles in inducing synaptic metaplasticity, we performed a global form of sensitivity analysis on our model, using an approach that was analogous to that taken in previous studies (Foster et al., 1993; Goldman et al., 2001; Prinz et al., 2003, 2004; Achard and De Schutter, 2006; Tobin et al., 2006; Hobbs and Hooper, 2008; Weaver and Wearne, 2008; Taylor et al., 2009; Rathour and Narayanan, 2012, 2014). Specifically, to generate a population of models for performing global sensitivity analysis, we first tuned a baseline model by incorporating all active conductances (NaF, KDR, CaR, CaT, KA, SK, HCN) into the model. The tuning was such that the modification threshold of the plasticity profile generated with this baseline model was around the experimentally observed value of $10 \mathrm{~Hz}$ (Dudek and Bear, 1992; Johnston et al., 2003; Cooper and Bear, 2012). Then, we randomized each of the 11 model parameters such that they uniformly and independently span a neighborhood around their default values (Table 1) to generate 20,000 models, each built with a unique set of values for the 11 parameters. We computed the modification threshold of the synaptic plasticity profile for each of these 20,000 models from their synaptic plasticity profiles and declared the model valid if this modification threshold fell within the experimentally observed range of 8-12 Hz (Dudek and Bear, 1992; Johnston et al., 2003). Of the 20,000 randomly generated models, we found $360(\sim 1.8 \%)$ to be valid, which we used for further analyses.

Virtual knock-out models. For quantitatively assessing the impact of individual channel conductances on the modification threshold, we used the recently developed virtual knock-out methodology within the global sensitivity analysis framework (Rathour and Narayanan, 2014). To elaborate, we analyzed the impact of different voltage-gated ion channels on the modification threshold by removing the conductance mediated by that channel from each of the 360 valid models. We removed a specific conductance from each of the 360 valid models and computed the mod- ification threshold of the synaptic plasticity profile from each VKM lacking this conductance. Then, we measured the percentage difference in this modification threshold with reference to the modification threshold in the corresponding baseline valid model (where all voltage-gated ion channels were intact) and represented the percentage differences obtained across the 360 VKMs as a histogram. We repeated this entire procedure for each of the seven different voltage-gated ion channels ( NaF, KDR, CaR, CaT, SK, KA, and HCN), obtaining the modification threshold in all 360 valid models (yielding a total of $7 \times 360=2520$ $\mathrm{VKMs}$ ) and plotted the percentage differences for each voltage-gated ion channel.

\section{Results}

Given the calcium dependence of the plasticity profile and the increase in calcium concentration with increase in induction frequency (Lisman, 1989, 2001; Shouval et al., 2002; Narayanan and Johnston, 2010; Cooper and Bear, 2012; Sehgal et al., 2013), it is reasonable to expect a leftward shift in the BCM-like plasticity profile with increase in voltage-gated calcium channel density. Similarly, based on the fact that SK channels mediate a restorative conductance, it stands to reason that the profile would shift toward the right with increase in SK channel density (Ngo-Anh et al., 2005; Lin et al., 2008; Luján et al., 2009; Adelman et al., 2012). However, detailed quantitative analyses on whether differences in voltage-dependent properties of the different dendritic voltage-gated calcium channels (Magee and Johnston, 1995; Randall and Tsien, 1997) translate to differential metaplastic profiles have not been performed. Furthermore, as SK channels are calcium-dependent conductances, they would form a feedback loop in conjunction with the voltage-gated calcium channels and NMDA receptors (Ngo-Anh et al., 2005; Lin et al., 2008; Luján et al., 2009; Adelman et al., 2012). How do SK channels interact with these different calcium sources? Do the voltage-dependent and kinetic properties of these channels alter the metaplastic profiles introduced by SK channels?

\section{$R$-type and $T$-type calcium channels differentially modulated the synaptic plasticity profile}

First, we addressed the question on whether the differences in voltage-dependent properties of $R$-type and $T$-type channels (Fig. 1C) translated to differences in the metaplasticity profile introduced by these channels. To do this, we introduced either $\mathrm{CaR}$ or $\mathrm{CaT}$ channels independently into our model that was endowed with the spike-generating conductances ( $\mathrm{NaF}$ and KDR). We constructed the plasticity profile for the 900-pulse protocol at different induction frequencies with various values of CaR (Fig. 1D) or CaT (Fig. 1E) conductance density, and plotted the modification threshold corresponding to these plasticity profiles as functions of $\mathrm{CaR}$ and $\mathrm{CaT}$ conductance density (Fig. $1 F$ ). Although the metaplastic shift in the profile was expectedly toward the left with increase in either conductance, there were significant quantitative differences in how this shift manifested (Fig. $1 F)$. First, for identical increases in conductance, the shift in the modification threshold was larger with increase in the CaT conductance than in the CaR conductance. Second, whereas the relatively small-magnitude leftward shift in the modification threshold was abrupt and saturated with further increase in CaR conductance, the shift induced by increase in CaT conductance was relatively linear, larger, and nonsaturating in the tested range (Fig. $1 F$ ).

We reasoned these differences to be direct consequences of the differences in voltage-dependent activation and inactivation profiles (Magee and Johnston, 1995; Randall and Tsien, 1997) of the $\mathrm{CaR}$ and the CaT conductances (Fig. 1C). Specifically, the 
A

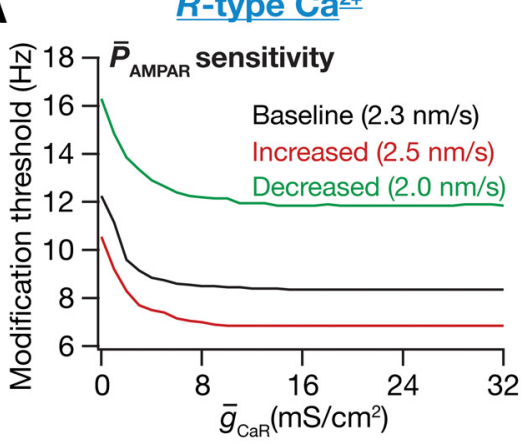

C

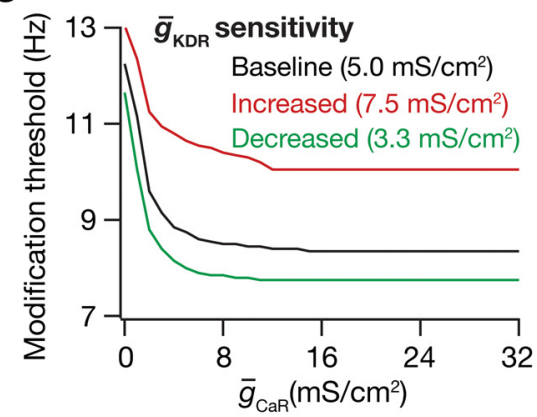

E

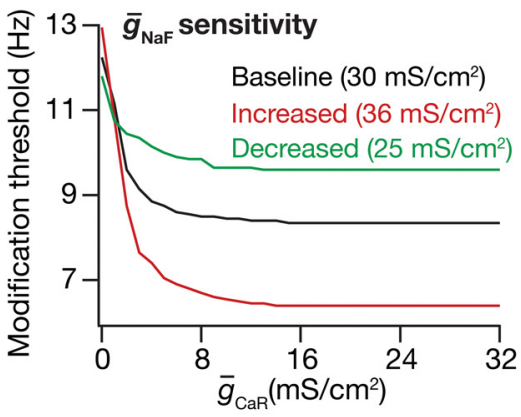

B

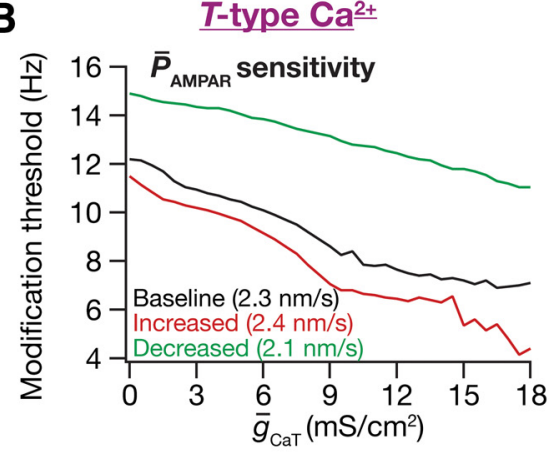

D

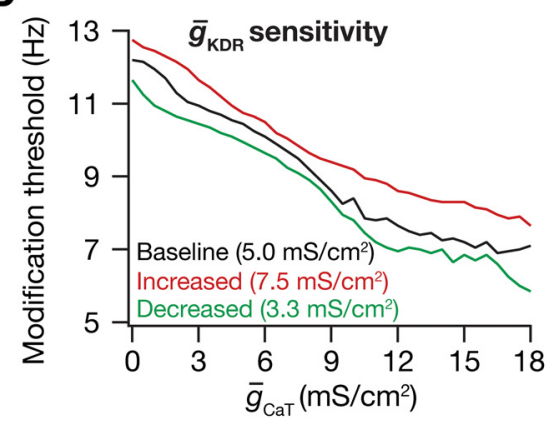

$\mathbf{F}$

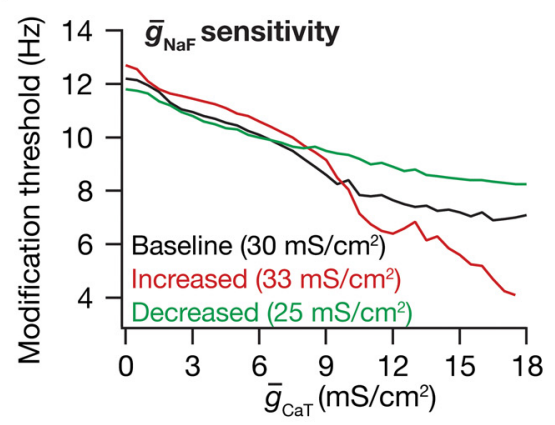

G

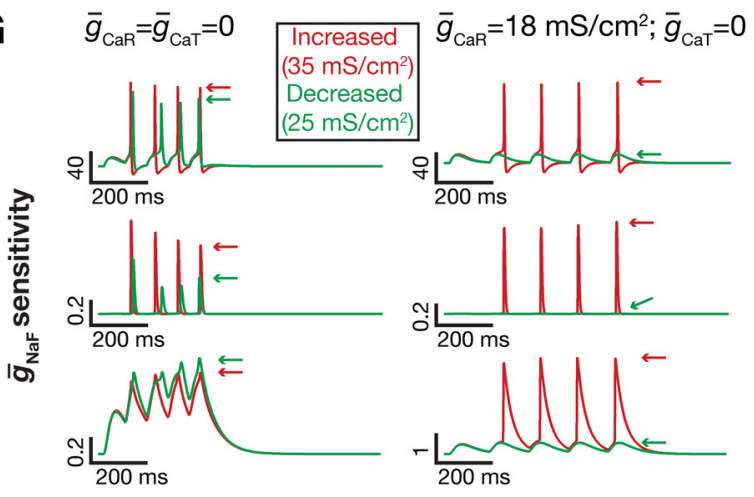

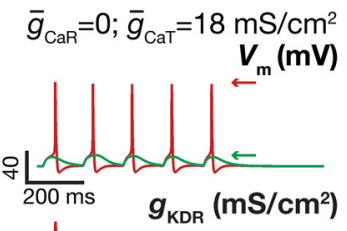
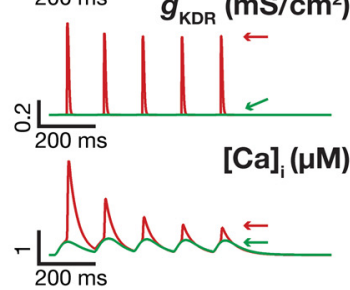

Figure 2. Sensitivity of modification threshold to $R$-type and $T$-type calcium channels under different parametric configurations. $\boldsymbol{A}-\boldsymbol{F}$, Modification threshold plotted as functions of $\mathrm{CaR}(\boldsymbol{A}, \boldsymbol{C}, \boldsymbol{E})$ and $\mathrm{CaT}(\boldsymbol{B}, \boldsymbol{D}, \boldsymbol{F})$ conductance density for various values of AMPAR permeability $(\boldsymbol{A}, \boldsymbol{B}), \operatorname{KDR}(\boldsymbol{C}, \boldsymbol{D})$, and $\operatorname{NaF}(\boldsymbol{E}, \boldsymbol{F})$ conductance density. $\boldsymbol{A}-\boldsymbol{F}$, The analyses correspond to models that contained the spike-generating conductances ( $\mathrm{NaF}$ and $\mathrm{KDR}$ ) and one of $\mathrm{CaR}$ or $\mathrm{CaT}$ channels. $\mathbf{G}$, Traces corresponding to NaF sensitivity analysis showing the cross-dependencies of the different channels in regulating intracellular calcium levels. Plots represent voltage (top), $g_{K D R}$ (middle), and intracellular calcium concentration (bottom) for 3 cases corresponding to the presence of only the spike-generating conductances (left), the copresence of either the $\mathrm{CaR}$ (center), or the CaT channels (right). Arrows indicate maximal values of the corresponding trace with reference to the last stimulation. The interstimulus interval for the 5 stimuli presented for the left traces was $75 \mathrm{~ms}$, and that for the center and the right traces was $140 \mathrm{~ms}$. The interstimulus interval values were designed to be closer to the modification threshold so that the differences between the parametric values are emphasized.

depolarized activation profile of the $\mathrm{CaR}$ conductance implies minimal activation during subthreshold activation ranges and an abrupt jump in calcium levels when action potential fire. The saturation of calcium elevation and the modification threshold, on the other hand, are a consequence of the limit imposed by the frequency of the fixed number of pulses (900) used in the induction protocol, whereby the number of action potentials fired during the induction protocol does not increase beyond a certain value. In contrast, the relatively hyperpolarized profiles of the CaT conductance (Fig. 1C) imply a larger subthreshold contribution to calcium elevation, thereby ensuring that an increase in CaT conductance effectively translates to changes in the modification threshold.

\section{Sensitivity analyses reveal intricate} cross-dependencies of channels in regulating the modification threshold Were our conclusions about the differential modulation of the modification threshold by the CaR and CaT channels specific to the choice of parameters in our simulations? To address this, we performed sensitivity analyses on the three prominent parameters in these simulations (AMPAR permeability, $\mathrm{NaF}$ and KDR conductance densities) and asked whether the differential modulation extended with different values of these parameters (Fig. 2). As expected (Narayanan and Johnston, 2010), whereas an increase in AMPAR permeability and $\mathrm{NaF}$ conductance led to an overall leftward shift in the modification threshold, an increase in KDR conductance induced a rightward shift in the plasticity profile. Despite these expected differences in the baseline plasticity profile, and importantly, the differential modulation of the modification threshold by $\mathrm{CaR}$ and $\mathrm{CaT}$ channels extended across all parametric combinations (Fig. 2). Specifically, we noted that an increase in CaR conductance led to a smaller saturating leftward shift in the modification threshold, but the shift induced by the CaT conductance was larger and nonsaturating. Together, these results suggested that the $\mathrm{CaR}$ and the CaT conductances differentially modulated the synaptic plasticity profile as a consequence of differences in their voltage-activation profiles.

Closer observation of the evolution of the modification threshold as functions of the CaT and $\mathrm{CaR}$ conductances revealed the distinction between the evolution of AMPAR (Fig. $2 A, B$ ) and KDR (Fig. 2C,D) plots and the evolution of $\mathrm{NaF}$ (Fig. $2 E, F$ ) plots. Specifically, across all values of $\mathrm{CaT}$ 
A

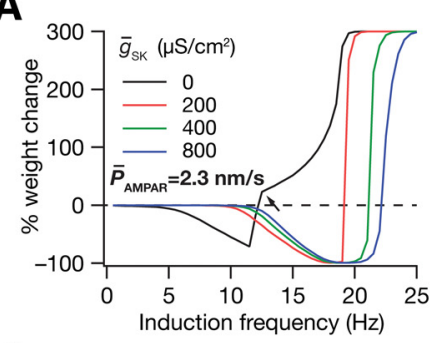

D

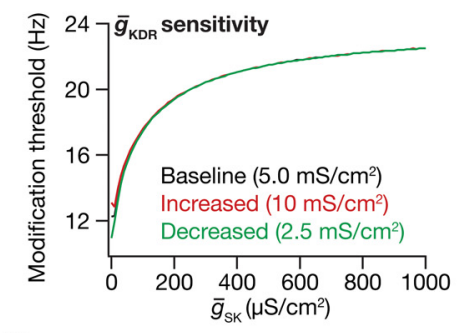

G

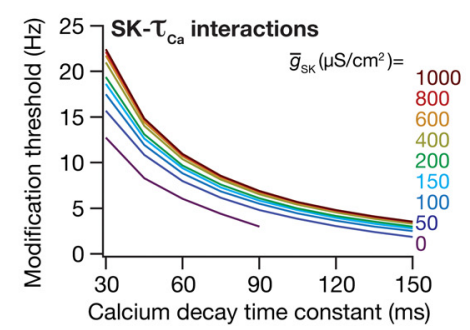

B

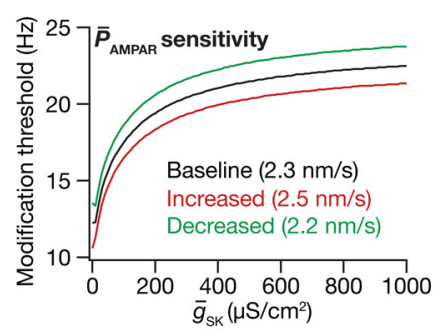

E

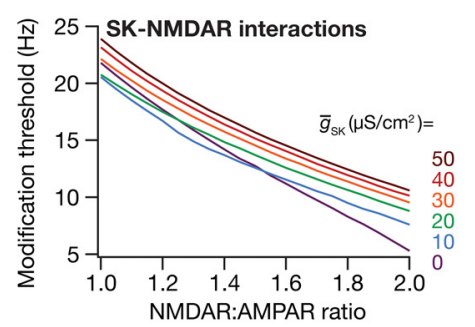

H

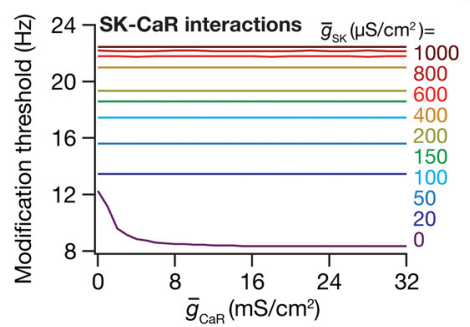

C

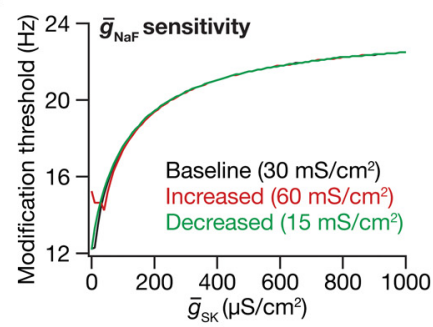

F

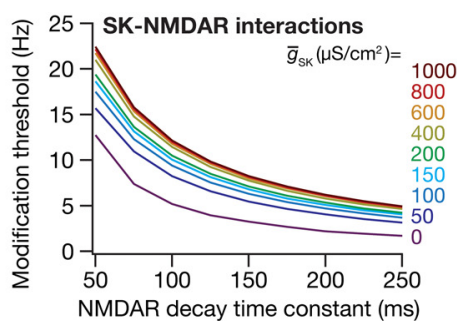

I

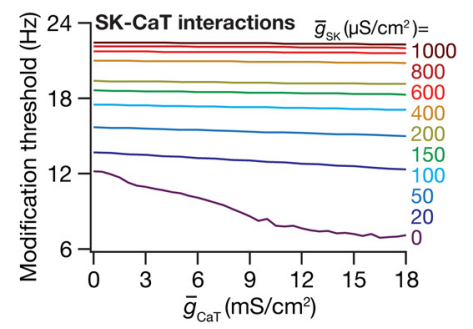

Figure 3. The small-conductance calcium-dependent potassium (SK) conductance differentially interacted with several calcium conductances in regulating the BCM-like plasticity profile. $A$, Synaptic plasticity profile as a function of various induction frequencies ( 900 pulses protocol) plotted for different values of $S K$ conductance density. Black arrows indicate sharp transitions in the synaptic plasticity profiles and correspond to induction frequency values where spikes were generated in response to synaptic stimulation. $\boldsymbol{B}-\boldsymbol{D}$, Modification threshold plotted as a function of $S K$ conductance density $\left(\bar{g}_{S K}\right)$ for various values of AMPAR permeability $(\boldsymbol{B}), \operatorname{NaF}(\boldsymbol{C})$, and KDR $(\boldsymbol{D})$ conductance density. $\boldsymbol{E}$, $\boldsymbol{F}$, Analyses of interactions between SK channels and NMDAR depicted as plots of modification threshold as a function of NMDAR:AMPAR ratio $(\boldsymbol{E})$ and NMDAR decay time constant $(\boldsymbol{F})$ for various values of $\bar{g}_{S K}$. $\boldsymbol{G}$, Modification threshold plotted as a function of calcium decay time constant (Eq. 10) for various values of $\bar{g}_{S K}$. A $-\mathbf{G}$, The analyses correspond to a model that contained only the NaF, KDR, and SK channels. $\boldsymbol{H}, \boldsymbol{I}$, Analyses of interactions between $S K$ channels and voltage-gated calcium channels depicted as plots of modification threshold as a function of $\mathrm{CaR}(\boldsymbol{H})$ and $\mathrm{CaT}(\boldsymbol{I})$ conductance densities.

and $\mathrm{CaR}$ conductance densities, an increase in AMPAR permeability (Fig. $2 A, B$ ) or a decrease in KDR conductance (Fig. 2C,D) consistently induced a leftward shift in the modification threshold, whereas opposite signs for these changes resulted in a rightward shift. However, an increase in $\mathrm{NaF}$ conductance resulted in a rightward shift for lower values of either $\mathrm{CaT}$ or $\mathrm{CaR}$ conductance, which progressively shifted to a leftward shift for higher values of the CaT or CaR conductance (Fig. 2E,F). A decrease in $\mathrm{NaF}$ conductance, on the other hand, transformed from a leftward shift to a rightward shift with progressive increase in either $\mathrm{CaT}$ or $\mathrm{CaR}$ conductance.

What was the mechanism behind an increase in the regenerative $\mathrm{NaF}$ conductance inducing a rightward shift in the modification threshold? To address this, we turned to the analyses presented by Narayanan and Johnston (2010), where a small increase in the restorative KA conductance resulted in a leftward shift, but transformed to a rightward shift upon larger increases in the KA conductance. There, the lesser activation of KDR conductance with smaller values of KA conductance was the reason behind the dichotomous impact of the KA conductance on the modification threshold (Narayanan and Johnston, 2010). Here, extrapolating from observations with NaF-KA-KDR interactions, we reasoned that at lower values of $\mathrm{CaR}$ or $\mathrm{CaT}$ conductance, the action potential amplitude would be larger, leading to a higher activation of the KDR conductance, which results in an abrupt reset of the calcium evolution, thereby curtailing the over- all calcium elevation (Fig. 2G). Thus, the activation of KDR conductance, a restorative conductance, and the consecutive reduction in calcium elevations lead to anomalous rightward shift that is observed with increase in $\mathrm{NaF}$ conductance. On the other hand, with higher values of either the CaR or the CaT conductance, the calcium elevation is higher because of this additional calcium influx through these channels. This, coupled with the inward current mediated by these calcium channels, ensures that even a small increase in $\mathrm{NaF}$ conductance translates to changes in the number of spikes, thereby leading to the expected leftward shift with increase in NaF conductance (Fig. $2 E-G)$.

\section{SK channels differentially interacted with several calcium sources to induce a saturating rightward shift in the synaptic plasticity profile}

How do SK channels regulate the modification threshold in conjunction with three calcium sources, the NMDA receptors, the $\mathrm{CaR}$ and the CaT channels? How do the properties of these channels and receptors alter the specifics of the interactions among them? Are the interactions different when more than one calcium source interacts with the SK channels? To address these questions, we first assessed the impact of SK channels in a model that contained the SK and the spike-generating channels, with NMDA receptors as the only calcium source (Fig. $3 A$ ). As expected from previous results and as SK channels mediate a restorative potas- 
sium conductance (Ngo-Anh et al., 2005; Lin et al., 2008; Luján et al., 2009; Adelman et al., 2012), an increase in SK conductance induced a rightward shift in the modification threshold (Fig. $3 A, B)$. Was this conclusion dependent on the specific choice of AMPAR permeability, and $\mathrm{NaF}$ and KDR conductances? To address this, we repeated our analyses with different values for all three parameters (Fig. $3 B-D$ ) and found that an increase in SK channel conductance resulted in an overall rightward shift in the modification threshold. The initial leftward shift observed in the $\mathrm{NaF}$ sensitivity profile (Fig. $3 \mathrm{C}$ ) was again a consequence of the SK-KDR interactions mentioned above and analyzed previously (Narayanan and Johnston, 2010).

Turning to interactions between the SK channels and NMDARs, we repeated our simulations with different values for the NMDAR:AMPAR ratio, NAR (Fig. $3 E$ ) and with different values of NMDAR decay time constant, $\tau_{\text {NMDAR }}$ (Fig. $3 F$ ), keeping AMPAR permeability to be the same across all these simulations. Whereas changes in NAR allowed us to assess the impact of the relative densities of these two receptors, changes in $\tau_{\text {NMDAR }}$ were used toward assessing the impact of relative expression profiles of the different NMDAR subunits (Philpot et al., 2001a, b, 2003; Shouval et al., 2002; Liu et al., 2004). Although an increase in either parameter elicited strong leftward shifts in the modification threshold (Shouval et al., 2002; Narayanan and Johnston, 2010), we noted that there were quantitative differences in the manner of this leftward shift (Fig. $3 E, F$ ) and in how they responded to changes in SK conductance. First, regardless of the value of SK conductance density, an increase in NAR led to a nonsaturating leftward shift (Fig. $3 E$ ) but that in $\tau_{\text {NMDAR }}$ resulted in a saturating leftward shift (Fig. $3 F$ ). We reasoned this to be consequent to the differential changes in EPSP shapes that increase in NAR and $\tau_{\text {NMDAR }}$ bring about. Specifically, an increase in NAR enhances the EPSP amplitude across the entire duration, and an increase in $\tau_{N M D A R}$ alters only the decay without altering the peak amplitude of the EPSP. This, in conjunction with the summation limit imposed by the induction frequencies used, and the manner in which calcium elevation translates to plasticity (Fig. 1B) implied that an increase in NAR would be more effective in altering the modification threshold than an increase in $\tau_{N M D A R}$.

Second, for lower values of NAR, small increases in SK conductance resulted in an anomalous leftward shift, which switched to the expected rightward shift for higher values of NAR or SK conductance density (Fig. 3E). Based on analyses similar to Figure $2 G$ and by Narayanan and Johnston (2010), we traced this effect to be a direct consequence of the SK-KDR interactions. Specifically, for lower values of SK conductance, the action potential amplitude was reduced, leading to a lesser activation of $\mathrm{KDR}$, which translated to the anomalous leftward shift in the modification threshold. For higher values of SK conductance, given the calcium dependence of plasticity (Fig. 1B), the restorative SK conductance induced a rightward shift in the modification threshold.

Calcium extrusion in neuronal compartments is a function of the specific on and off mechanisms present in the compartment, apart from the morphology of the compartment. To quantitatively understand the impact of how calcium extrusion is effectuated in the compartment and how SK channels interact with altered calcium decay times in altering synaptic plasticity profile, we performed an interaction-sensitivity analysis (Fig. $3 G$ ) on SK conductance density and calcium decay time constant, $\tau_{C a}$ (Eq. 10). A higher value for $\tau_{C a}$ implies enhanced temporal summation of calcium, thereby leading a leftward shift in the plasticity profile. On the other hand, a larger value of $\tau_{C a}$ would leave more intracellular calcium for the activation of SK channels, implying an enhanced restorative effect on excitability leading to a rightward shift in the modification threshold with an increase in SK channel density. How do these contrasting effects of increasing $\tau_{C a}$ in the presence of SK channels interact? When we performed the interaction analysis, we found that increase in $\tau_{C a}$ shifted the modification threshold toward the left regardless of the density of SK channels (Fig. 3G). However, at lower values of $\tau_{C a}$, the SKdependent rightward shift in the modification threshold was larger, but with increase in $\tau_{C a}$, this rightward shift becomes smaller (Fig. $3 G$ ), suggesting the dominance of $\tau_{C a}$-dependent leftward shift when $\tau_{\mathrm{Ca}}$ was larger.

Finally, we performed interaction analyses on SK conductance density with various $\mathrm{CaR}$ (Fig. $3 H$ ) and $\mathrm{CaT}$ (Fig. 3I) conductance densities and found that, at higher values, the SK conductance played the dominant role in regulating the sliding modification threshold. Although the impact of either $\mathrm{CaR}$ or $\mathrm{CaT}$ on the modification was insignificant at higher values of SK conductance, at smaller SK conductance values, both SK and the calcium conductances together governed the modification threshold.

The conclusions presented in Figure 3 were derived from a simple Hodgkin-Huxley-type SK channel model. How dependent were our conclusions on the specific choice of this simplified Hodgkin-Huxley-type SK channel model? Would these conclusions hold if a detailed multistate kinetic scheme were used to model SK channels? To address these questions and to especially rule out the possibility of dependence of our conclusions on the specific Hodgkin-Huxley-type model chosen for the SK current, we repeated our experiments in Figure 3 with a 6-state macroscopic kinetic model of the SK current (Fig. 4A) obtained from CA1 pyramidal neurons (Sah and Isaacson, 1995; Sah and Clements, 1999). To do this, we first plotted the SK-channel steadystate activation curve as a function of cytosolic calcium concentration (Fig. 4A) and confirmed that its properties matched with those specified for this model (Sah and Clements, 1999). Specifically, we noted that the curve has a steep activation above the resting concentration of cytosolic calcium ( $50 \mathrm{nM}$ ) with a half-maximal activation concentration of $\sim 150 \mathrm{nM}$ and a peak open probability of $\sim 0.6$ (Fig. $4 A$ ). Having validated the model, we repeated our experiments on interactions of SK channels with various calcium sources using this 6-state model for SK channels. Except for differences in the range of SK channel conductances associated with Hodgkin-Huxley-type (Fig. 3) and 6-state model (Fig. 4), which is to be expected because of differences in model definition, we found that the interactions of SK channels with several calcium sources and associated parameters were very similar in terms of how they regulated the sliding modification threshold, regardless of the specific model used (compare Fig. $3 B-I$ with Fig. $4 B-I)$.

Together, and in conjunction with earlier observations (Shouval et al., 2002; Sjöström et al., 2008; Narayanan and Johnston, 2010; Ashhad and Narayanan, 2013; Honnuraiah and Narayanan, 2013), these results (Figs. 1, 2, and 3) uncover the tight mutual interdependence of several dendritically expressed ion channels and receptors in regulating the modification threshold. It should be noted that the quantitative aspects of the interdependent manner in which different conductances alter the modification threshold are critically reliant on the specific form of the function that relates plasticity to calcium elevation (Fig. $1 B$ ) and the functions that govern the voltage dependence and kinetics of the different ion channels and receptors. 
A 6-state SK-channel model

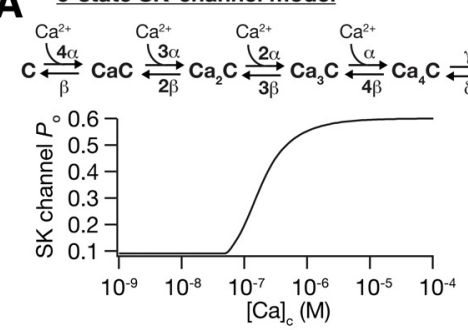

D

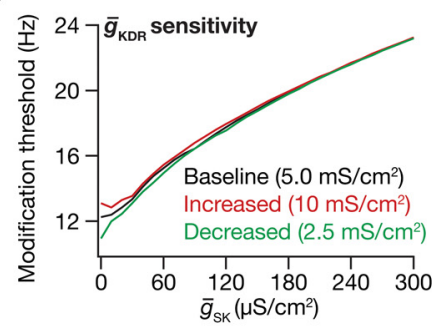

G

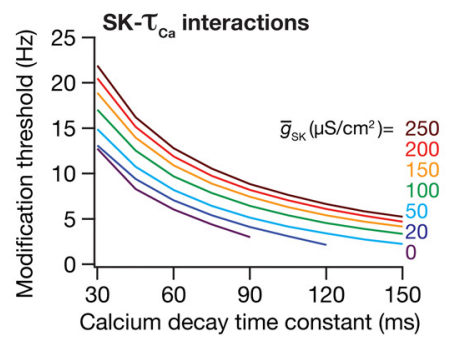

B

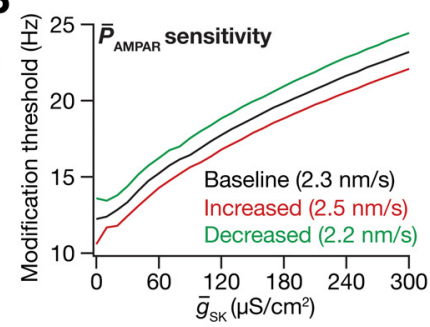

E

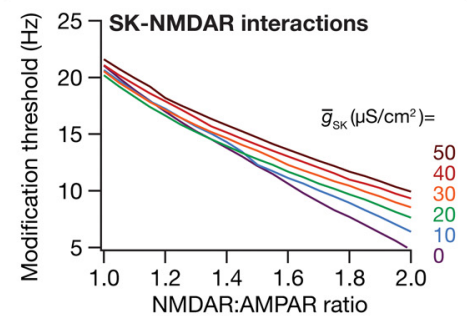

H

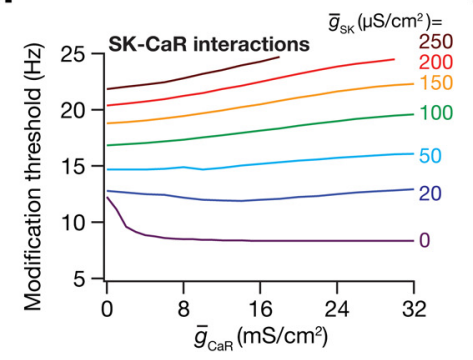

C

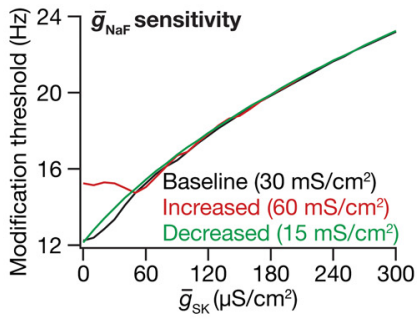

F

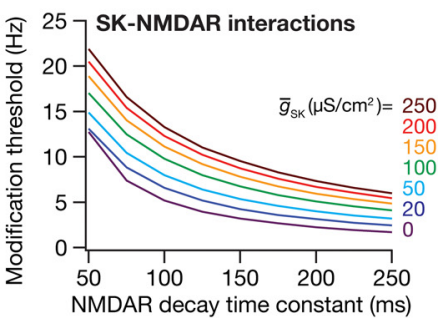

I

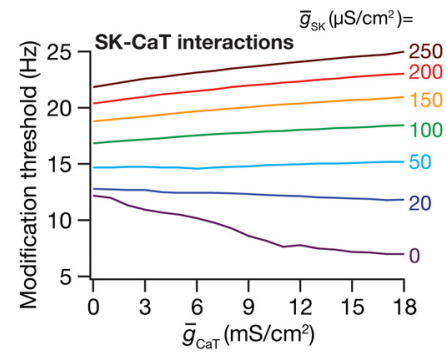

Figure 4. The small-conductance calcium-dependent potassium (SK) conductance, modeled as a 6-state kinetic scheme, differentially interacted with several calcium conductances in regulating the BCM-like plasticity profile. A, Top, Six-state kinetic model of SK channels in CA1 pyramidal neurons adopted previously (Sah and Isaacson, 1995; Sah and Clements, 1999). Parametric values were as follows: $\alpha=10 \mu \mathrm{m} / \mathrm{s}, \beta=0.5 / \mathrm{s}, \gamma=600 / \mathrm{s}$, and $\delta=400 / \mathrm{s}$. Bottom, Activation curve of the 6-state SK channel model plotted as a function of cytosolic calcium concentration. $\boldsymbol{B}-\boldsymbol{D}$, Modification threshold plotted as a function of $S K$ conductance density $\left(\bar{g}_{S K}\right)$ for various values of AMPAR permeability $(\boldsymbol{B}), \operatorname{NaF}(\boldsymbol{C})$, and KDR (D) conductance density. $\boldsymbol{E}, \boldsymbol{F}$, Analyses of interactions between SK channels and NMDAR depicted as plots of modification threshold as a function of NMDAR:AMPAR ratio $(\boldsymbol{E})$ and NMDAR decay time constant $(\boldsymbol{F})$ for various values of $\bar{g}_{S K}$. $\boldsymbol{G}$, Modification threshold plotted as a function of calcium decay time constant (Eq. 10) for various values of $\bar{g}_{S K}$. A-G, The analyses correspond to a model that contained only the NaF, KDR, and the 6-state SK channel model. $\boldsymbol{H}, \boldsymbol{I}$, Analyses of interactions between SK channels and voltage-gated calcium channels depicted as plots of modification threshold as a function of $\mathrm{CaR}(\boldsymbol{H})$ and $\mathrm{CaT}(\boldsymbol{I})$ conductance densities.

\section{Emergence of plasticity profile homeostasis despite the absence of individual or pairwise channelostasis}

From the analyses presented above, it was evident that several ion channels critically contribute to the determination of the synaptic plasticity profile. Measurements of the ion channel and receptor density of these neurons through a variety of techniques have demonstrated that there is significant neuron-to-neuron variability in channel conductances and their properties (Magee and Johnston, 1995; Hoffman et al., 1997; Magee, 1998; Andrasfalvy and Magee, 2001; Chen and Johnston, 2004). Despite this, synapse types exhibit similar plasticity profiles unless they are subjected to metaplasticity that is consequent to behavior or pathology (Abraham, 2008; Hulme et al., 2013). How do neurons maintain their synaptic plasticity profiles in the face of such variability in channel and receptor densities? How do plasticity profiles at individual synapses retain their identities despite baseline turnover and activity-dependent plasticity of channels and receptors (Marder and Goaillard, 2006; Marder, 2011; Hanus and Schuman, 2013)? Do channel and receptor densities need strict maintenance at specific values for maintaining synaptic plasticity profiles? Are correlations in the expression profiles of channels and receptors required for the maintenance of plasticity profile homeostasis?

Addressing these questions required that we account for all interactions across several voltage-gated ion channels and recep- tors that are expressed in hippocampal pyramidal neuron dendrites. Although the interaction sensitivity analyses presented above and in other studies (Shouval et al., 2002; Sjöström et al., 2008; Narayanan and Johnston, 2010; Ashhad and Narayanan, 2013; Honnuraiah and Narayanan, 2013) was sufficient for assessing pairwise interactions, they fall short in accounting for interactions across all channels and receptors. Therefore, we turned to the powerful global sensitivity analysis methodology (Foster et al., 1993; Goldman et al., 2001; Prinz et al., 2003, 2004; Achard and De Schutter, 2006; Tobin et al., 2006; Hobbs and Hooper, 2008; Weaver and Wearne, 2008; Taylor et al., 2009; Rathour and Narayanan, 2012, 2014) and designed it such that it encompasses all the receptors and channels that were part of the sensitivity analysis. Specifically, we incorporated the seven dendritically expressed voltage-gated ion conductances (NaF, KDR, $\mathrm{CaR}, \mathrm{CaT}, \mathrm{KA}, \mathrm{SK}, \mathrm{HCN}$ ), the permeabilities of the two synaptic receptors (AMPAR and NMDAR), and the two decay-time constants $\left(\tau_{N M D A R}, \tau_{C a}\right)$ that played an important role in regulating the modification threshold (Figs. 1, 2, and 3) (Shouval et al., 2002; Sjöström et al., 2008; Narayanan and Johnston, 2010; Ashhad and Narayanan, 2013; Honnuraiah and Narayanan, 2013).

We generated 20,000 randomized models such that each model had a unique set of these 11 parameters uniformly spanning a range of values mentioned in Table 1 . We constructed the 
A

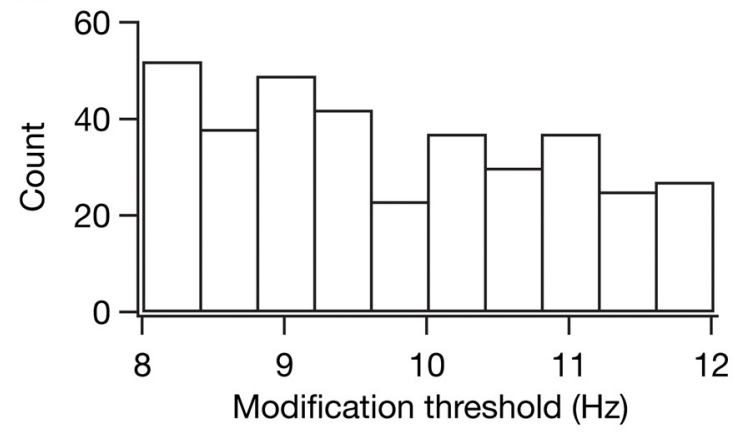

\section{C}

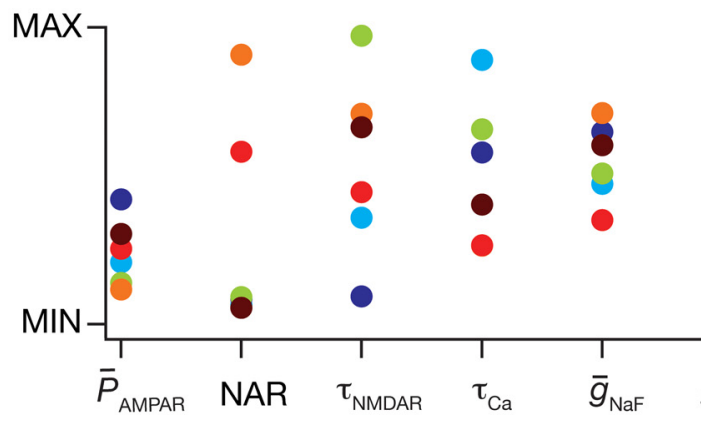

B
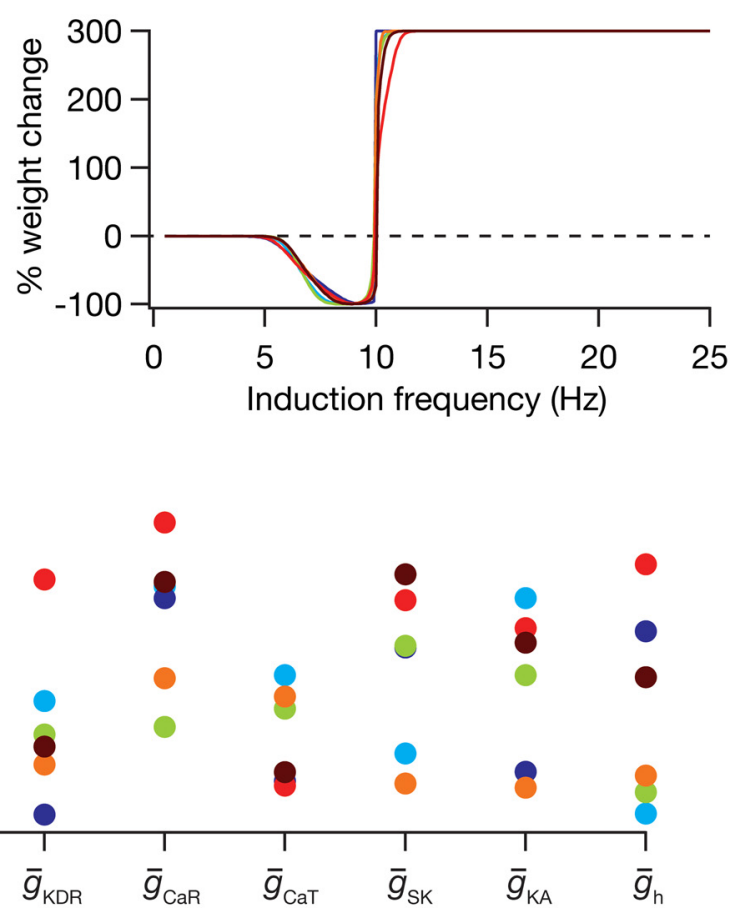

Figure 5. Analogous plasticity profiles emerged in the absence of individual channelostasis. $\boldsymbol{A}$, Histogram of modification threshold obtained from the 360 valid models. $\boldsymbol{B}$, Plasticity profiles from six valid models chosen such that they are similar to each other across induction frequencies. $\boldsymbol{C}$, Distribution of the 11 underlying model parameters in the six valid model neurons (corresponding to $\boldsymbol{A})$ depicted along with their respective minimum-maximum range. Each colored dot indicates parameters of the color-matched model whose plasticity profile is depicted in $\boldsymbol{B}$.

synaptic plasticity profile for these 20,000 models (see Models and Methods) and declared a model to be valid if the modification threshold for the model was between $8 \mathrm{~Hz}$ and $12 \mathrm{~Hz}$. This range was determined to be around the experimentally observed $10 \mathrm{~Hz}$ (Dudek and Bear, 1992; Johnston et al., 2003), and to quantitatively assess the parameters underlying the emergence of very similar synaptic plasticity profiles. Of the 20,000 randomly generated models, we found $360(\sim 1.8 \%)$ to be valid with the modification threshold distributed over $8-12 \mathrm{~Hz}$ (Fig. $5 A$ ).

In analyzing these 360 valid models and their parametric distributions, we first picked six models that had their synaptic plasticity profile nearly identical, with the modification threshold very close to $10 \mathrm{~Hz}$ (Fig. $5 \mathrm{~B}$ ). We analyzed the 11 parameters that resulted in these six models and asked whether they were disparate or formed clusters. When we plotted each of the 11 parameters against their respective minimum and maximal values (Table 1 ), we found that parameters across these models almost spanned the entire range of possible values, with no prominent clustering in parameters (Fig. $5 C$ ). We also plotted the histograms of the parameters associated with all the 360 valid models (not just the six chosen ones) and found that they were distributed across the entire range of their possible values (Fig. 6A, bottom). Such emergence of plasticity profile robustness (Fig. $5 A, B$ ) despite disparate (Figs. $5 C$ and $6 A$ ), nonunique combinations of conductances and other parametric values clearly suggested that plasticity profile homeostasis does not require individual channelostasis.

Under this scenario where individual channels did not need to maintain strict adherence to specific conductance values for achieving plasticity profile homeostasis, did pairwise interactions between them guide plasticity profile homeostasis? Specifically, were changes in one particular conductance compensated by changes specific to another conductance, thereby nullifying the impact on changes in the modification threshold? To address this, we performed pairwise correlation analysis on the 11 parameters from each of the 360 valid models (Fig. 6) and found that 52 of the 55 unique pairs had an absolute correlation coefficient value, $|R|$, to be $<0.3\left(R^{2}<0.09\right.$; Fig. 6$)$. Such weak pairwise correlations between channel densities and other parameters clearly indicated that pairwise channelostasis was also expendable in achieving plasticity profile homeostasis. Specifically, these results indicated that robust similarity in plasticity profiles was achieved through a scenario where multiple parametric changes compensated for a change in one parameter, rather than a tightly coupled pairwise compensatory regimen. Together, these results offered clear evidence that individual and pairwise channelostasis were not essential in the maintenance of plasticity profile homeostasis and that several nonunique channel-receptor combinations could yield similar, if not identical, synaptic plasticity profiles.

\section{Virtual knock-out models revealed the differential and variable impact of different ion channels on synaptic metaplasticity}

The results above suggest a collective form of channelostasis, where the underlying ion channels regulate themselves in an apparently uncorrelated manner (Fig. 6), as a distinct alternative for individual/pairwise channelostasis in achieving plasticity profile homeostasis (Fig. 5). In this regimen where different channels contributed to plasticity homeostasis, did each of them contribute differently to the modification threshold or were their contributions quantitatively identical? What was the consequence of removing individual conductances from the model in terms of how that altered the modification threshold?

To address these questions, we used the VKM technique introduced by Rathour and Narayanan (2014) to assess the relative contribution of each channel to the modification threshold (Fig. 
$\mathbf{A}_{\bar{P}}$

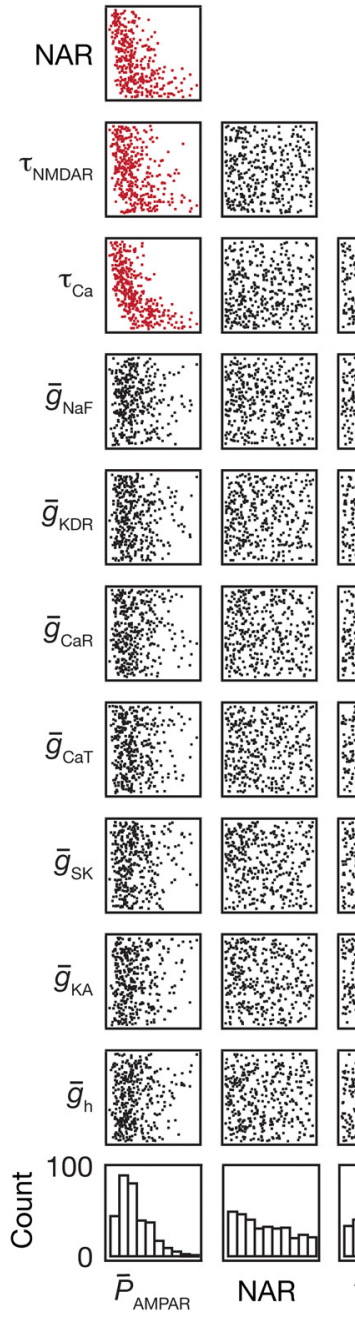

B
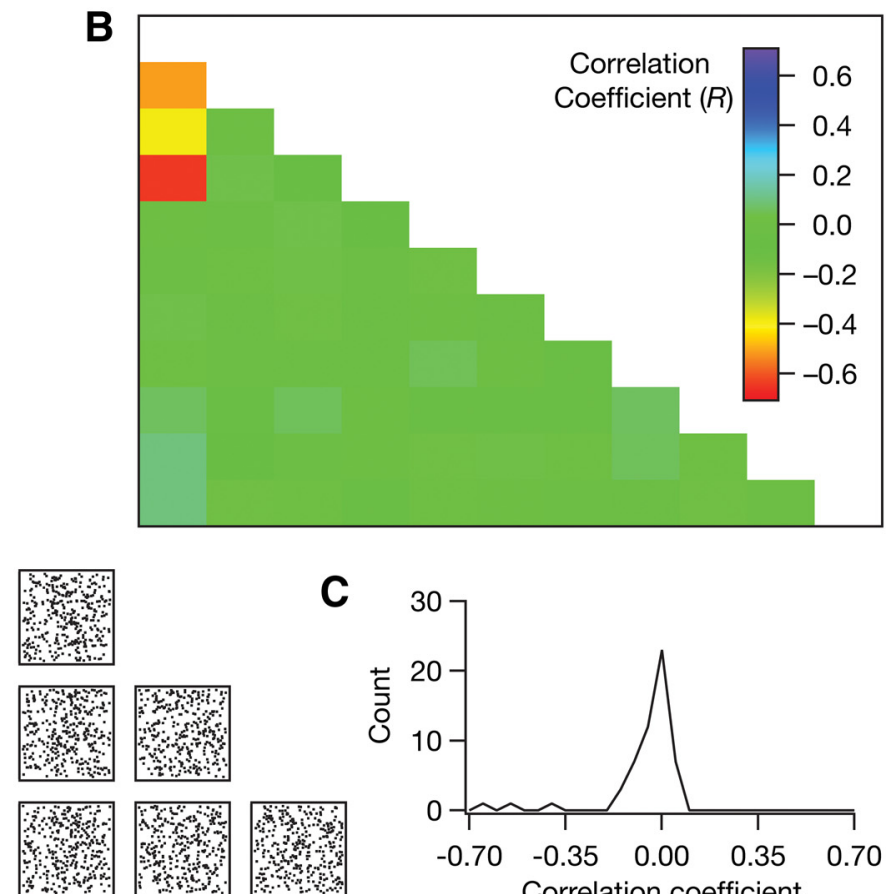

C

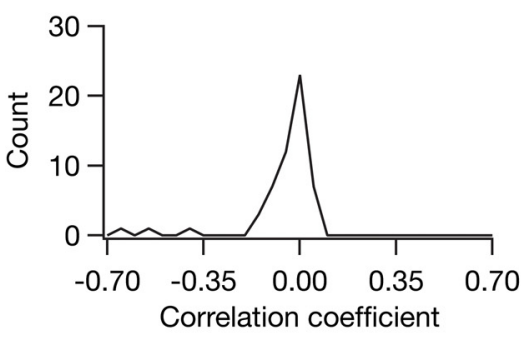

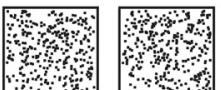
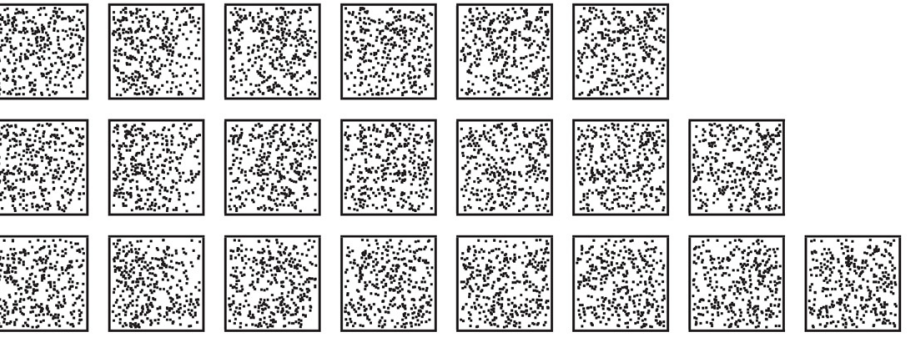

15.t.
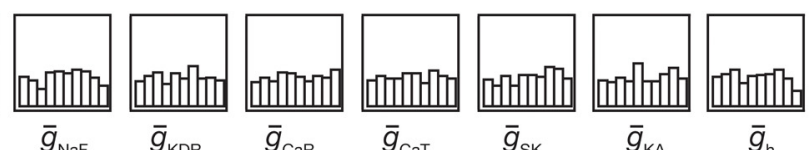

Figure 6. Plasticity profile homeostasis emerged despite weak pairwise correlations across parameters. $A$, Lower diagonal of a matrix depicting interactions among the 11 parameters derived from all 360 valid models. Each subpanel represents a scatter plot of the values of two parameters (labeled below and left) derived from all valid models. Correlation coefficients were computed for each of the scatter plots. Red scatter plots represent that the value of the correlation coefficient was $<-0.3$. Bottom-most row, Normalized histograms of individual parameters in the valid model population. $\boldsymbol{B}$, Lower diagonal of a color-coded matrix of correlation coefficients corresponding to the scatter plots in $\boldsymbol{A}$. $\boldsymbol{C}$, Distribution of correlation coefficients for the 55 pairs corresponding to the scatter plots in $\boldsymbol{A}$.

7). Specifically, we constructed the synaptic plasticity profile for each of the 360 valid models by deleting each of the seven ion channel conductances, one at a time, and compared the modification threshold obtained after virtual knock-out of the conductance with that before knock-out. This procedure revealed that the impact of deleting any individual ion channel was variable, with some models showing a larger change in the modification threshold and other showing significantly lower or no change (Fig. 7). We attributed this to the variable distribution of ion channels across models (Figs. 5 and 6), where a larger or smaller conductance value for the specific channel under consideration would lead to a larger or smaller change in the modification threshold, respectively, upon virtual knock-out of that conductance. Although this variability in the amplitude of change was observed across each of the different ion channels, we noted that the change in modification threshold followed consistent directions upon deletion of specific channels. Specifically, whereas the deletion of the regenerative $\mathrm{NaF}, \mathrm{CaR}$, and $\mathrm{CaT}$ conductances led to a rightward shift in the plasticity profile, the deletion of the restorative $\mathrm{KDR}, \mathrm{KA}, \mathrm{SK}$, and $\mathrm{HCN}$ conductances resulted in a leftward shift (Fig. $7 \mathrm{H}$ ). It should be noted that the average shift in the modification threshold brought about by the CaR conductance is relatively lower because of its depolarized voltage dependence profiles and the observation that the modification threshold undergoes a small saturating shift with increase in the $\mathrm{CaR}$ conductance density (Figs. 1 and 2). Together, these results using virtual knock-out models revealed the differential and variable contributions of the different dendritic ion channels to the modification threshold.

\section{Discussion}

The primary conclusion of this study is that plasticity homeostasis can emerge in the absence of individual and paired channelostasis. This implies that several nonunique channel configurations can result in similar, if not identical, plasticity profiles and that any form of metaplasticity could be achieved through several disparate routes. In arriving at these conclusions, we first performed interaction sensitivity analyses to complement those in 
A

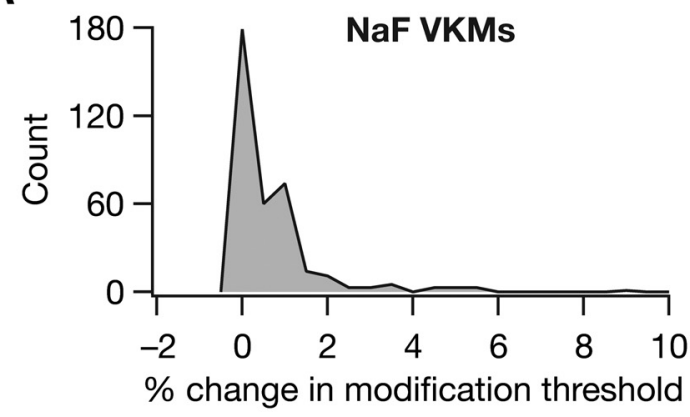

C

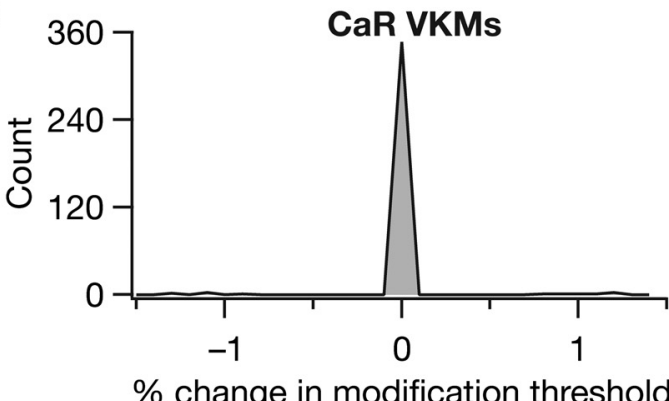

$\mathbf{E}$

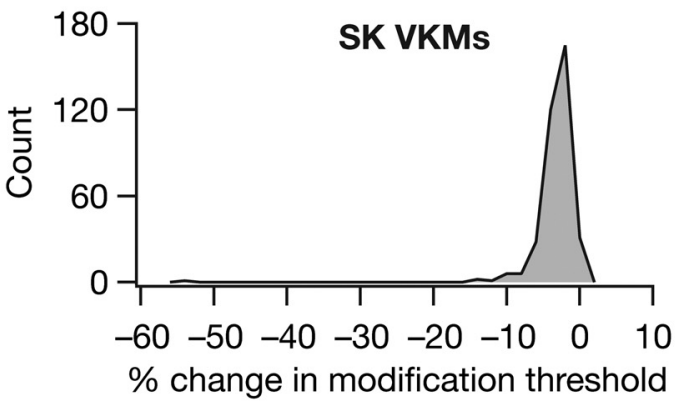

B

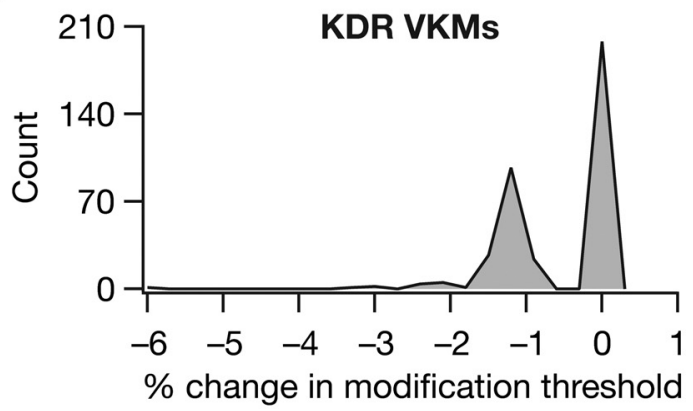

D

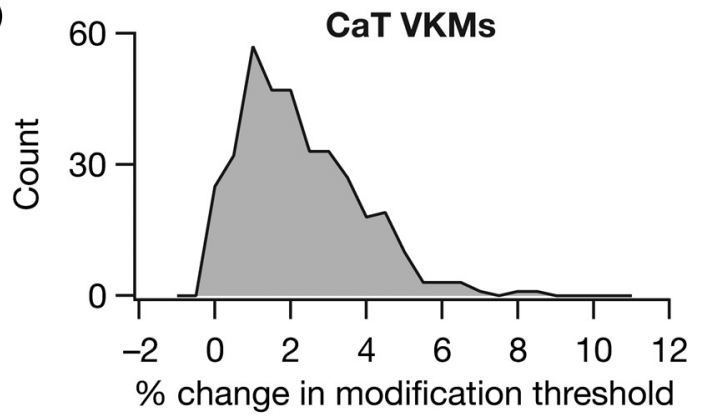

$\mathbf{F}$
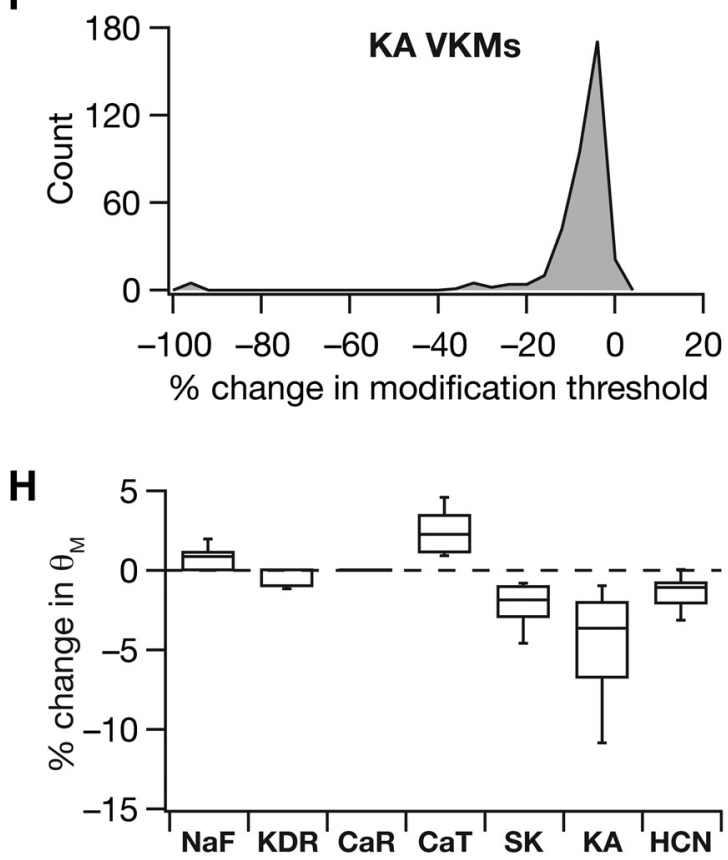

Figure 7. Virtual knock-out of specific conductances from the population of valid models revealed the differential impact of different ion channels on the synaptic plasticity profile. $A-G$, Distributions of percentage changes in the modification threshold after virtual knock-out of $\mathrm{NaF}(\boldsymbol{A}), \mathrm{KDR}(\boldsymbol{B}), \mathrm{CaR}(\boldsymbol{C})$, CaT (D), SK (E), KA (F), and HCN $(\boldsymbol{G})$ conductances from the valid model population of 360 models. $\boldsymbol{H}$, Percentage change (represented as median and the quartiles; bottom, 10\%; top, $90 \%$ ) in the modification threshold after virtual knock-out of each of the seven conductances.

existing studies. These analyses demonstrated that the voltage dependence profiles and kinetics of voltage-gated calcium channels contribute significantly to their differential impact on the synaptic plasticity profile. Further, performing interaction sensitivity analyses on SK channels with several calcium sources and parameters that alter calcium extrusion, we demonstrated that these interactions are heavily dependent on how these parameters interact with synaptic and action potentials to alter their impact on calcium evolution. Finally, using the powerful global sensitiv- ity analysis on all the dendritic ion channels and other critical parameters of the model, we demonstrated the differential contribution of each channel to the modification threshold.

Several nonidentical routes to metaplasticity and plasticity profile homeostasis

Within the BCM theory for synaptic modification, an open question concerns the specific mechanism that is responsible for regulating the sliding modification threshold (Bienenstock et al., 
1982; Abraham and Bear, 1996; Abraham and Tate, 1997; Abraham, 2008; Cooper and Bear, 2012). Several mechanisms, including NMDA receptor signaling and subunit composition, calcium buffering, CaMKII and HCN channels have been proposed as candidates for this critical regulation (Gold and Bear, 1994; Bear, 1995; Mayford et al., 1995; Abraham and Bear, 1996; Abraham and Tate, 1997; Philpot et al., 2001a, b, 2003; Bear, 2003; Abraham, 2008; Honnuraiah and Narayanan, 2013; Hulme et al., 2013; Sehgal et al., 2013). Our results clearly demonstrate that there need not be one route to implementing modification threshold. We show that it is possible that a neuron could take several nonunique routes involving distinct channels and receptors to achieve the required metaplasticity shift in synaptic plasticity profile. Against this, we postulate that identical shifts in the plasticity profiles could be achieved by recruiting disparate channels/receptors and that the specific metaplastic mechanism recruited by a neuron toward regulating the sliding modification threshold is variable and state-dependent. Under such a postulate, signaling components, such as CaMKII, would be accommodated in their role as sensors of calcium that alter synaptic receptors and ionic conductances toward achieving a specific metaplastic shift in the plasticity profile (Mayford et al., 1995; Lisman et al., 2002; Sjöström and Häusser, 2006; Shah et al., 2010; Turrigiano, 2011; Lisman et al., 2012). Specifically, several kinases and phosphatases regulate the specific direction and strength of synaptic and intrinsic plasticity. Corresponding changes in synaptic receptors and ion channels could also effectuate the metaplastic shift that might be essential in regulating the sliding modification threshold, thereby implicating these signaling mechanisms as regulators of the plasticity profile. Thus, in the study of metaplasticity and its importance for physiology and pathophysiology, it is essential that the mechanisms underlying that specific form of metaplasticity be carefully teased apart. A generalized mechanism that governs all forms of shifts in the modification threshold might not be feasible against the postulate of a state-dependent regulatory regimen.

\section{Channelostasis in complex dendritic trees for maintaining plasticity profiles}

The channels and receptors analyzed in this study are dendritically expressed in hippocampal pyramidal neurons and maintain precise subcellular localization profile (Magee and Johnston, 1995; Hoffman et al., 1997; Magee, 1998; Andrasfalvy and Magee, 2001; Migliore and Shepherd, 2002; Spruston, 2008; Luján et al., 2009; Narayanan and Johnston, 2012; Nusser, 2012). Apart from baseline turnover, these channels and receptors also undergo significant neuromodulation and plasticity with different loci of plasticity across the somatodendritic axis (Cantrell and Catterall, 2001; Johnston et al., 2003; Perez-Reyes, 2003; Johnston and Narayanan, 2008; Remy et al., 2010; Narayanan and Johnston, 2012; Shah, 2012; Hofmann et al., 2014). Against this and given that each of these channels and receptors can induce metaplasticity, how do synapses maintain specific profiles for synaptic plasticity across various locations of the somatodendritic arbor, especially when the plasticity profile is known to be different across locations (Froemke et al., 2005; Sjöström and Häusser, 2006; Sjöström et al., 2008)? Although the problem of targeting and localization of proteins to specific locations in neurons with dendritic arborization is extremely complex (Lai and Jan, 2006; Vacher et al., 2008; Hanus and Schuman, 2013), our observation that individual or pairwise channelostasis is not necessary for maintaining plasticity homeostasis offers a neuron with multiple routes to achieve this (Rathour and Narayanan, 2014).
In this context, a recent study proposes a self-regulating cellautonomous framework for the maintenance of single-neuron calcium homeostasis through calcium-dependent transcription and translation of channels and receptors in single neurons (O'Leary et al., 2014). Future studies should explore whether a simple homeostatic rule where only the baseline calcium concentration is maintained is adequate under a scenario where homeostasis of plasticity profile also needs maintenance. Specifically, the maintenance of homeostasis of calcium-dependent plasticity profiles of the different channels/receptors requires that specific levels of calcium elevation be achieved with specific frequencies (or patterns) of stimulation. It is possible that even models with identical levels of average calcium could respond differently to different frequencies of stimulation because of the differences in conductance values. Therefore, it is imperative that additional constraints on the levels of calcium elevation in response to a range of stimulation frequencies might have to be incorporated into a cell-autonomous homeostasis framework. Therefore, future studies should focus on specifying specific set points for both activity (calcium) and plasticity profiles (calcium elevation levels) into the framework for activity homeostasis (O'Leary et al., 2014) to maintain neuronal states that satisfy both the constraints.

Although our study incorporated several of the prominent dendritic ion channels that contribute to synaptic metaplasticity, there are other channels and receptors that we have not considered in this analysis. Prominent among these are the neuromodulatory inputs, the inhibitory receptors $\left(G_{A B A} R\right.$ and $G_{A B A} R$ ) and their interactions with other channels including the G-protein coupled inward-rectifying potassium (GIRK) channels. Incorporation of these are especially important because of the significant role that feedforward/feedback inhibition plays in regulating plasticity of excitatory synapses, and the critical role that GIRK channels play in mediating and modulating synaptic plasticity through interactions with other channels and receptors (Chung et al., 2009a; b; Luján et al., 2009; Turrigiano, 2011; Sanders et al., 2013). Future studies could incorporate feedforward/ feedback inhibitory stimuli with appropriate latencies with reference to the excitatory stimuli, the $\mathrm{GABA}_{\mathrm{B}} \mathrm{R}-\mathrm{GIRK}-\mathrm{NMDAR}$ interactions, and neuromodulatory influences on all these parameters within the global sensitivity framework in assessing their roles in regulating synaptic plasticity profiles and their homeostasis. In doing this, these studies should assess proteostasis as a whole (Balch et al., 2008; Hanus and Schuman, 2013), rather than being confined by only channelostasis, incorporating signaling microdomains (Ngo-Anh et al., 2005; Rizzuto and Pozzan, 2006; Neves et al., 2008) and associated reaction-diffusion system within a much broader plasticity framework (Kotaleski and Blackwell, 2010; O’Leary et al., 2014).

\section{Experimental support on our conclusions with virtual knock-out models}

Our analyses of the relative impact of each channel using virtual knock-out models revealed the differential and variable impact of different channels on the synaptic plasticity profile. Although direct experimental evidence with the 900-pulse protocol with different induction frequencies is lacking for most conclusions, they are broadly consistent with experimental and theoretical evidence in the literature. Specifically, it is known that blocking or knock-out of KA (Watanabe et al., 2002; Johnston et al., 2003; Chen et al., 2006), HCN (Nolan et al., 2004), and SK (Ngo-Anh et al., 2005; Luján et al., 2009; Adelman et al., 2012) channels enhance LTP. Additionally, CaT (Golding et al., 2002) and CaR (Yasuda et al., 2003; Takahashi and Magee, 2009) channels con- 
tribute to the induction of synaptic plasticity by acting as calcium sources, and blocking either channel reduces or abolishes LTP. Finally, theoretical evidence from interaction analyses in our study (Figs. 1, 2, and 3) and earlier studies (Narayanan and Johnston, 2010; Ashhad and Narayanan, 2013; Honnuraiah and Narayanan, 2013) lends additional support to the direction and strength of metaplasticity suggested by the virtual knock-out of specific channels (Fig. 7). Although our study has focused on the plasticity profile with reference to the 900-pulse multiplefrequencies protocol for synaptic plasticity, future studies could assess the role of these channels and receptors in altering other forms of plasticity, such as spike-timing dependent plasticity (Magee and Johnston, 1997; Markram et al., 1997; Bi and Poo, 1998; Shouval et al., 2002; Sjöström et al., 2008) and in the plasticity of ion channels (Zhang and Linden, 2003; Frick and Johnston, 2005; Magee and Johnston, 2005; Kim and Linden, 2007; Johnston and Narayanan, 2008; Mozzachiodi and Byrne, 2010; Remy et al., 2010; Shah et al., 2010; Turrigiano, 2011; Narayanan and Johnston, 2012). Such analyses should focus on metaplasticity under both physiological as well as pathophysiological conditions (Hulme et al., 2013).

In conclusion, our results provide clear lines of evidence that there are several nonunique routes to homeostasis of plasticity profiles and to metaplasticity. Extrapolation of these analyses to behavioral correlates of neuronal plasticity implies that learning might occur through recruitment of several disparate cellular components of diverse sets of neurons across several nonunique sets of brain regions (O'Leary and Marder, 2014). They also suggest that the pathways recruited by pathophysiological conditions and injury might be extremely variable, even if activity and plasticity profiles have shifted by similar magnitude and directions (Marder and Goaillard, 2006; Marder and Taylor, 2011; O'Leary et al., 2014). These observations call for a systematic and a thorough analysis of the multiple routes and variability associated with the mechanisms for metaplasticity, and their implications for behavior and pathology.

\section{References}

Abraham WC (2008) Metaplasticity: tuning synapses and networks for plasticity. Nat Rev Neurosci 9:387. CrossRef Medline

Abraham WC, Bear MF (1996) Metaplasticity: the plasticity of synaptic plasticity. Trends Neurosci 19:126-130. CrossRef Medline

Abraham WC, Tate WP (1997) Metaplasticity: a new vista across the field of synaptic plasticity. Prog Neurobiol 52:303-323. CrossRef Medline

Achard P, De Schutter E (2006) Complex parameter landscape for a complex neuron model. PLoS Comput Biol 2:e94. CrossRef Medline

Adelman JP, Maylie J, Sah P (2012) Small-conductance $\mathrm{Ca}^{2+}$-activated $\mathrm{K}^{+}$ channels: form and function. Annu Rev Physiol 74:245-269. CrossRef Medline

Andrasfalvy BK, Magee JC (2001) Distance-dependent increase in AMPA receptor number in the dendrites of adult hippocampal CA1 pyramidal neurons. J Neurosci 21:9151-9159. Medline

Ashhad S, Narayanan R (2013) Quantitative interactions between the A-type $\mathrm{K}^{+}$current and inositol trisphosphate receptors regulate intraneuronal $\mathrm{Ca}^{2+}$ waves and synaptic plasticity. J Physiol 591:1645-1669. CrossRef Medline

Balch WE, Morimoto RI, Dillin A, Kelly JW (2008) Adapting proteostasis for disease intervention. Science 319:916-919. CrossRef Medline

Bear MF (1995) Mechanism for a sliding synaptic modification threshold. Neuron 15:1-4. CrossRef Medline

Bear MF (2003) Bidirectional synaptic plasticity: from theory to reality. Philos Trans R Soc Lond B Biol Sci 358:649-655. CrossRef Medline

Bernard C, Shah M, Johnston D (2007) Dendrites and disease. In: Dendrites, Ed 2 (Stuart G, Spruston N, Häusser M, eds). Oxford: Oxford UP.

Bi GQ, Poo MM (1998) Synaptic modifications in cultured hippocampal neurons: dependence on spike timing, synaptic strength, and postsynaptic cell type. J Neurosci 18:10464-10472. Medline
Bienenstock EL, Cooper LN, Munro PW (1982) Theory for the development of neuron selectivity: orientation specificity and binocular interaction in visual cortex. J Neurosci 2:32-48. Medline

Brager DH, Johnston D (2014) Channelopathies and dendritic dysfunction in fragile X syndrome. Brain Res Bull 103:11-17. CrossRef Medline

Canavier CC (1999) Sodium dynamics underlying burst firing and putative mechanisms for the regulation of the firing pattern in midbrain dopamine neurons: a computational approach. J Comput Neurosci 6:49-69. CrossRef Medline

Cantrell AR, Catterall WA (2001) Neuromodulation of $\mathrm{Na}^{+}$channels: an unexpected form of cellular plasticity. Nat Rev Neurosci 2:397-407. CrossRef Medline

Carnevale NT, Hines ML (2006) The NEURON book. Cambridge: Cambridge UP.

Chen X, Johnston D (2004) Properties of single voltage-dependent $\mathrm{K}^{+}$ channels in dendrites of CA1 pyramidal neurones of rat hippocampus. J Physiol 559:187-203. CrossRef Medline

Chen X, Yuan LL, Zhao C, Birnbaum SG, Frick A, Jung WE, Schwarz TL, Sweatt JD, Johnston D (2006) Deletion of Kv4.2 gene eliminates dendritic A-type $\mathrm{K}^{+}$current and enhances induction of long-term potentiation in hippocampal CA1 pyramidal neurons. J Neurosci 26:12143-12151. CrossRef Medline

Chung HJ, Qian X, Ehlers M, Jan YN, Jan LY (2009a) Neuronal activity regulates phosphorylation-dependent surface delivery of G proteinactivated inwardly rectifying potassium channels. Proc Natl Acad Sci U S A 106:629-634. CrossRef Medline

Chung HJ, Ge WP, Qian X, Wiser O, Jan YN, Jan LY (2009b) G proteinactivated inwardly rectifying potassium channels mediate depotentiation of long-term potentiation. Proc Natl Acad Sci U S A 106:635-640. CrossRef Medline

Cooper LN, Bear MF (2012) The BCM theory of synapse modification at 30: interaction of theory with experiment. Nat Rev Neurosci 13:798-810. CrossRef Medline

Dingledine R, Borges K, Bowie D, Traynelis SF (1999) The glutamate receptor ion channels. Pharmacol Rev 51:7-61. Medline

Dudek SM, Bear MF (1992) Homosynaptic long-term depression in area CA1 of hippocampus and effects of $N$-methyl-D-aspartate receptor blockade. Proc Natl Acad Sci U S A 89:4363-4367. CrossRef Medline

Ferrante M, Migliore M, Ascoli GA (2013) Functional impact of dendritic branch-point morphology. J Neurosci 33:2156-2165. CrossRef Medline

Foster WR, Ungar LH, Schwaber JS (1993) Significance of conductances in Hodgkin-Huxley models. J Neurophysiol 70:2502-2518. Medline

Frick A, Johnston D (2005) Plasticity of dendritic excitability. J Neurobiol 64:100-115. CrossRef Medline

Froemke RC, Poo MM, Dan Y (2005) Spike-timing-dependent synaptic plasticity depends on dendritic location. Nature 434:221-225. CrossRef Medline

Gasparini S, Migliore M, Magee JC (2004) On the initiation and propagation of dendritic spikes in CA1 pyramidal neurons. J Neurosci 24:1104611056. CrossRef Medline

Gold JI, Bear MF (1994) A model of dendritic spine $\mathrm{Ca}^{2+}$ concentration exploring possible bases for a sliding synaptic modification threshold. Proc Natl Acad Sci U S A 91:3941-3945. CrossRef Medline

Golding NL, Staff NP, Spruston N (2002) Dendritic spikes as a mechanism for cooperative long-term potentiation. Nature 418:326-331. CrossRef Medline

Goldman DE (1943) Potential, impedance, and rectification in membranes. J Gen Physiol 27:37-60. CrossRef Medline

Goldman MS, Golowasch J, Marder E, Abbott LF (2001) Global structure, robustness, and modulation of neuronal models. J Neurosci 21:52295238. Medline

Hanus C, Schuman EM (2013) Proteostasis in complex dendrites. Nat Rev Neurosci 14:638-648. CrossRef Medline

Hobbs KH, Hooper SL (2008) Using complicated, wide dynamic range driving to develop models of single neurons in single recording sessions. J Neurophysiol 99:1871-1883. CrossRef Medline

Hodgkin AL, Katz B (1949) The effect of sodium ions on the electrical activity of giant axon of the squid. J Physiol 108:37-77. CrossRef Medline

Hoffman DA, Magee JC, Colbert CM, Johnston D (1997) $\mathrm{K}^{+}$channel regulation of signal propagation in dendrites of hippocampal pyramidal neurons. Nature 387:869-875. CrossRef Medline

Hofmann F, Flockerzi V, Kahl S, Wegener JW (2014) L-type CaV1.2 cal- 
cium channels: from in vitro findings to in vivo function. Physiol Rev 94:303-326. CrossRef Medline

Honnuraiah S, Narayanan R (2013) A calcium-dependent plasticity rule for HCN channels maintains activity homeostasis and stable synaptic learning. PLoS One 8:e55590. CrossRef Medline

Hulme SR, Jones OD, Abraham WC (2013) Emerging roles of metaplasticity in behaviour and disease. Trends Neurosci 36:353-362. CrossRef Medline

Jahr CE, Stevens CF (1990) Voltage dependence of NMDA-activated macroscopic conductances predicted by single-channel kinetics. J Neurosci 10:3178-3182. Medline

Johnston D, Narayanan R (2008) Active dendrites: colorful wings of the mysterious butterflies. Trends Neurosci 31:309-316. CrossRef Medline

Johnston D, Christie BR, Frick A, Gray R, Hoffman DA, Schexnayder LK, Watanabe S, Yuan LL (2003) Active dendrites, potassium channels and synaptic plasticity. Philos Trans R Soc Lond B Biol Sci 358:667-674. CrossRef Medline

Kim SJ, Linden DJ (2007) Ubiquitous plasticity and memory storage. Neuron 56:582-592. CrossRef Medline

Kotaleski JH, Blackwell KT (2010) Modelling the molecular mechanisms of synaptic plasticity using systems biology approaches. Nat Rev Neurosci 11:239-251. CrossRef Medline

Krichmar JL, Nasuto SJ, Scorcioni R, Washington SD, Ascoli GA (2002) Effects of dendritic morphology on CA3 pyramidal cell electrophysiology: a simulation study. Brain Res 941:11-28. CrossRef Medline

Lai HC, Jan LY (2006) The distribution and targeting of neuronal voltagegated ion channels. Nat Rev Neurosci 7:548-562. CrossRef Medline

Lee HY, Jan LY (2012) Fragile X syndrome: mechanistic insights and therapeutic avenues regarding the role of potassium channels. Curr Opin Neurobiol 22:887-894. CrossRef Medline

LeMasson G, Marder E, Abbott LF (1993) Activity-dependent regulation of conductances in model neurons. Science 259:1915-1917. CrossRef Medline

Lin MT, Luján R, Watanabe M, Adelman JP, Maylie J (2008) SK2 channel plasticity contributes to LTP at Schaffer collateral-CA1 synapses. Nat Neurosci 11:170-177. CrossRef Medline

Lisman J (1989) A mechanism for the Hebb and the anti-Hebb processes underlying learning and memory. Proc Natl Acad Sci U S A 86:95749578. CrossRef Medline

Lisman JE (2001) Three $\mathrm{Ca}^{2+}$ levels affect plasticity differently: the LTP zone, the LTD zone and no man's land. J Physiol 532:285. CrossRef Medline

Lisman J, Schulman H, Cline H (2002) The molecular basis of CaMKII function in synaptic and behavioural memory. Nat Rev Neurosci 3:175190. CrossRef Medline

Lisman J, Yasuda R, Raghavachari S (2012) Mechanisms of CaMKII action in long-term potentiation. Nat Rev Neurosci 13:169-182. CrossRef Medline

Liu L, Wong TP, Pozza MF, Lingenhoehl K, Wang Y, Sheng M, Auberson YP, Wang YT (2004) Role of NMDA receptor subtypes in governing the direction of hippocampal synaptic plasticity. Science 304:1021-1024. CrossRef Medline

Liu Z, Golowasch J, Marder E, Abbott LF (1998) A model neuron with activity-dependent conductances regulated by multiple calcium sensors. J Neurosci 18:2309-2320. Medline

Luján R, Maylie J, Adelman JP (2009) New sites of action for GIRK and SK channels. Nat Rev Neurosci 10:475-480. CrossRef Medline

Magee JC (1998) Dendritic hyperpolarization-activated currents modify the integrative properties of hippocampal CA1 pyramidal neurons. J Neurosci 18:7613-7624. Medline

Magee JC, Johnston D (1995) Characterization of single voltage-gated $\mathrm{Na}^{+}$ and $\mathrm{Ca}^{2+}$ channels in apical dendrites of rat CA1 pyramidal neurons. J Physiol 487:67-90. CrossRef Medline

Magee JC, Johnston D (1997) A synaptically controlled, associative signal for Hebbian plasticity in hippocampal neurons. Science 275:209-213. CrossRef Medline

Magee JC, Johnston D (2005) Plasticity of dendritic function. Curr Opin Neurobiol 15:334-342. CrossRef Medline

Mainen ZF, Sejnowski TJ (1996) Influence of dendritic structure on firing pattern in model neocortical neurons. Nature 382:363-366. CrossRef Medline
Marder E (2011) Variability, compensation, and modulation in neurons and circuits. Proc Natl Acad Sci U S A 108 [Suppl 3]:15542-15548.

Marder E, Goaillard JM (2006) Variability, compensation and homeostasis in neuron and network function. Nat Rev Neurosci 7:563-574. CrossRef Medline

Marder E, Prinz AA (2002) Modeling stability in neuron and network function: the role of activity in homeostasis. Bioessays 24:1145-1154. CrossRef Medline

Marder E, Taylor AL (2011) Multiple models to capture the variability in biological neurons and networks. Nat Neurosci 14:133-138. CrossRef Medline

Markram H, Lübke J, Frotscher M, Sakmann B (1997) Regulation of synaptic efficacy by coincidence of postsynaptic APs and EPSPs. Science 275: 213-215. CrossRef Medline

Mayer ML, Westbrook GL (1987) Permeation and block of N-methyl-Daspartic acid receptor channels by divalent cations in mouse cultured central neurones. J Physiol 394:501-527. CrossRef Medline

Mayford M, Wang J, Kandel ER, O'Dell TJ (1995) CaMKII regulates the frequency-response function of hippocampal synapses for the production of both LTD and LTP. Cell 81:891-904. CrossRef Medline

Migliore M, Shepherd GM (2002) Emerging rules for the distributions of active dendritic conductances. Nat Rev Neurosci 3:362-370. CrossRef Medline

Migliore M, Hoffman DA, Magee JC, Johnston D (1999) Role of an A-type $\mathrm{K}^{+}$conductance in the back-propagation of action potentials in the dendrites of hippocampal pyramidal neurons. J Comput Neurosci 7:5-15. CrossRef Medline

Mozzachiodi R, Byrne JH (2010) More than synaptic plasticity: role of nonsynaptic plasticity in learning and memory. Trends Neurosci 33:17-26. CrossRef Medline

Narayanan R, Chattarji S (2010) Computational analysis of the impact of chronic stress on intrinsic and synaptic excitability in the hippocampus. J Neurophysiol 103:3070-3083. CrossRef Medline

Narayanan R, Johnston D (2010) The h current is a candidate mechanism for regulating the sliding modification threshold in a BCM-like synaptic learning rule. J Neurophysiol 104:1020-1033. CrossRef Medline

Narayanan R, Johnston D (2012) Functional maps within a single neuron. J Neurophysiol 108:2343-2351. CrossRef Medline

Neves SR, Tsokas P, Sarkar A, Grace EA, Rangamani P, Taubenfeld SM, Alberini CM, Schaff JC, Blitzer RD, Moraru II, Iyengar R (2008) Cell shape and negative links in regulatory motifs together control spatial information flow in signaling networks. Cell 133:666-680. CrossRef Medline

Ngo-Anh TJ, Bloodgood BL, Lin M, Sabatini BL, Maylie J, Adelman JP (2005) SK channels and NMDA receptors form a $\mathrm{Ca}^{2+}$-mediated feedback loop in dendritic spines. Nat Neurosci 8:642-649. CrossRef Medline

Nolan MF, Malleret G, Dudman JT, Buhl DL, Santoro B, Gibbs E, Vronskaya S, Buzsáki G, Siegelbaum SA, Kandel ER, Morozov A (2004) A behavioral role for dendritic integration: HCN1 channels constrain spatial memory and plasticity at inputs to distal dendrites of CA1 pyramidal neurons. Cell 119:719-732. CrossRef Medline

Nusser Z (2012) Differential subcellular distribution of ion channels and the diversity of neuronal function. Curr Opin Neurobiol 22:366-371. CrossRef Medline

O'Leary T, Marder E (2014) Mapping neural activation onto behavior in an entire animal. Science 344:372-373. CrossRef Medline

O'Leary T, Williams AH, Franci A, Marder E (2014) Cell types, network homeostasis, and pathological compensation from a biologically plausible ion channel expression model. Neuron 82:809-821. CrossRef Medline

Perez-Reyes E (2003) Molecular physiology of low-voltage-activated T-type calcium channels. Physiol Rev 83:117-161. CrossRef Medline

Philpot BD, Sekhar AK, Shouval HZ, Bear MF (2001a) Visual experience and deprivation bidirectionally modify the composition and function of NMDA receptors in visual cortex. Neuron 29:157-169. CrossRef Medline

Philpot BD, Weisberg MP, Ramos MS, Sawtell NB, Tang YP, Tsien JZ, Bear MF (2001b) Effect of transgenic overexpression of NR2B on NMDA receptor function and synaptic plasticity in visual cortex. Neuropharmacology 41:762-770. CrossRef Medline

Philpot BD, Espinosa JS, Bear MF (2003) Evidence for altered NMDA receptor function as a basis for metaplasticity in visual cortex. J Neurosci 23:5583-5588. Medline

Poirazi P, Brannon T, Mel BW (2003) Arithmetic of subthreshold synaptic 
summation in a model CA1 pyramidal cell. Neuron 37:977-987. CrossRef Medline

Poolos NP, Johnston D (1999) Calcium-activated potassium conductances contribute to action potential repolarization at the soma but not the dendrites of hippocampal CA1 pyramidal neurons. J Neurosci 19:52055212. Medline

Prinz AA, Billimoria CP, Marder E (2003) Alternative to hand-tuning conductance-based models: construction and analysis of databases of model neurons. J Neurophysiol 90:3998-4015. CrossRef Medline

Prinz AA, Bucher D, Marder E (2004) Similar network activity from disparate circuit parameters. Nat Neurosci 7:1345-1352. CrossRef Medline

Randall AD, Tsien RW (1997) Contrasting biophysical and pharmacological properties of T-type and R-type calcium channels. Neuropharmacology 36:879-893. CrossRef Medline

Rathour RK, Narayanan R (2012) Inactivating ion channels augment robustness of subthreshold intrinsic response dynamics to parametric variability in hippocampal model neurons. J Physiol 590:5629-5652. CrossRef Medline

Rathour RK, Narayanan R (2014) Homeostasis of functional maps in active dendrites emerges in the absence of individual channelostasis. Proc Natl Acad Sci U S A 111:E1787-E1796. CrossRef Medline

Remy S, Beck H, Yaari Y (2010) Plasticity of voltage-gated ion channels in pyramidal cell dendrites. Curr Opin Neurobiol 20:503-509. CrossRef Medline

Rizzuto R, Pozzan T (2006) Microdomains of intracellular $\mathrm{Ca}^{2+}$ : molecular determinants and functional consequences. Physiol Rev 86:369-408. CrossRef Medline

Sah P, Clements JD (1999) Photolytic manipulation of $\left[\mathrm{Ca}^{2+}\right]$ i reveals slow kinetics of potassium channels underlying the afterhyperpolarization in hippocampal pyramidal neurons. J Neurosci 19:3657-3664. Medline

Sah P, Isaacson JS (1995) Channels underlying the slow afterhyperpolarization in hippocampal pyramidal neurons: neurotransmitters modulate the open probability. Neuron 15:435-441. CrossRef Medline

Sanders H, Berends M, Major G, Goldman MS, Lisman JE (2013) NMDA and GABAB (KIR) conductances: the "perfect couple" for bistability. J Neurosci 33:424-429. CrossRef Medline

Schaefer AT, Larkum ME, Sakmann B, Roth A (2003) Coincidence detection in pyramidal neurons is tuned by their dendritic branching pattern. J Neurophysiol 89:3143-3154. CrossRef Medline

Sehgal M, Song C, Ehlers VL, Moyer JR Jr (2013) Learning to learn: intrinsic plasticity as a metaplasticity mechanism for memory formation. Neurobiol Learn Mem 105:186-199. CrossRef Medline

Shah MM (2012) HCN1 channels: a new therapeutic target for depressive disorders? Sci Signal 5:pe44. CrossRef Medline

Shah MM (2014) Cortical HCN channels: function, trafficking and plasticity. J Physiol 592:2711-2719. CrossRef Medline

Shah MM, Hammond RS, Hoffman DA (2010) Dendritic ion channel trafficking and plasticity. Trends Neurosci 33:307-316. CrossRef Medline

Shouval HZ, Bear MF, Cooper LN (2002) A unified model of NMDA receptor-dependent bidirectional synaptic plasticity. Proc Natl Acad Sci U S A 99:10831-10836. CrossRef Medline

Siegel M, Marder E, Abbott LF (1994) Activity-dependent current distributions in model neurons. Proc Natl Acad Sci U S A 91:11308-11312. CrossRef Medline
Sjöström PJ, M (2006) A cooperative switch determines the sign of synaptic plasticity in distal dendrites of neocortical pyramidal neurons. Neuron 51:227-238. CrossRef Medline

Sjöström PJ, Rancz EA, Roth A, Häusser M (2008) Dendritic excitability and synaptic plasticity. Physiol Rev 88:769-840. CrossRef Medline

Spruston N (2008) Pyramidal neurons: dendritic structure and synaptic integration. Nat Rev Neurosci 9:206-221. CrossRef Medline

Takahashi H, Magee JC (2009) Pathway interactions and synaptic plasticity in the dendritic tuft regions of CA1 pyramidal neurons. Neuron 62:102111. CrossRef Medline

Taylor AL, Goaillard JM, Marder E (2009) How multiple conductances determine electrophysiological properties in a multicompartment model. J Neurosci 29:5573-5586. CrossRef Medline

Tobin AE, Van Hooser SD, Calabrese RL (2006) Creation and reduction of a morphologically detailed model of a leech heart interneuron. J Neurophysiol 96:2107-2120. CrossRef Medline

Triesch J (2007) Synergies between intrinsic and synaptic plasticity mechanisms. Neural Comput 19:885-909. CrossRef Medline

Turrigiano G (2011) Too many cooks? Intrinsic and synaptic homeostatic mechanisms in cortical circuit refinement. Annu Rev Neurosci 34:89103. CrossRef Medline

Turrigiano G, Abbott LF, Marder E (1994) Activity-dependent changes in the intrinsic properties of cultured neurons. Science 264:974-977. CrossRef Medline

Vacher H, Mohapatra DP, Trimmer JS (2008) Localization and targeting of voltage-dependent ion channels in mammalian central neurons. Physiol Rev 88:1407-1447. CrossRef Medline

van Elburg RA, van Ooyen A (2010) Impact of dendritic size and dendritic topology on burst firing in pyramidal cells. PLoS Comput Biol 6:e1000781. CrossRef Medline

van Ooyen A, Duijnhouwer J, Remme MW, van Pelt J (2002) The effect of dendritic topology on firing patterns in model neurons. Network 13:311325. CrossRef Medline

Vetter P, Roth A, Häusser M (2001) Propagation of action potentials in dendrites depends on dendritic morphology. J Neurophysiol 85:926-937. Medline

Watanabe S, Hoffman DA, Migliore M, Johnston D (2002) Dendritic K ${ }^{+}$ channels contribute to spike-timing dependent long-term potentiation in hippocampal pyramidal neurons. Proc Natl Acad Sci U S A 99:83668371. CrossRef Medline

Weaver CM, Wearne SL (2008) Neuronal firing sensitivity to morphologic and active membrane parameters. PLoS Comput Biol 4:e11. CrossRef Medline

Yasuda R, Sabatini BL, Svoboda K (2003) Plasticity of calcium channels in dendritic spines. Nat Neurosci 6:948-955. CrossRef Medline

Yuen GL, Durand D (1991) Reconstruction of hippocampal granule cell electrophysiology by computer simulation. Neuroscience 41:411-423. CrossRef Medline

Zhang W, Linden DJ (2003) The other side of the engram: experiencedriven changes in neuronal intrinsic excitability. Nat Rev Neurosci 4:885900. CrossRef Medline 